\title{
Redemptive Stories and Those Who Tell Them are Preferred in the U.S.
}

\author{
Kate C. McLean (Kate.McLean@wwu.edu) \\ Brianna C. Delker ${ }^{1}$ (delkerb@wwu.ed) \\ William L. Dunlop ${ }^{2}$ (william.dunlop@ucr.edu) \\ Rowan Salton ${ }^{1}$ (saltonr@wwu.edu) \\ Moin Syed³ (moin@umn.edu) \\ ${ }^{1}$ Western Washington University \\ ${ }^{2}$ University of California, Riverside \\ ${ }^{3}$ University of Minnesota
}

(in press). To appear in Collabra.

Acknowledgements. We are grateful to: Annie Riggs and Shaun Sowell for comments on an earlier draft of this manuscript; the Center for Cross Cultural Research for providing a grant to Kate McLean and Brianna Delker to support this study; the University of Minnesota for providing a Grand Challenges Exploratory Research Grant to Moin Syed to support this study. 


\begin{abstract}
The present studies examined the common, but untested, theoretical assumption that those in the United States prefer negative past experiences, such as trauma, to be redeemed, to be resolved in some positive or growth-promoting fashion. Narratives of six types of traumatic events that were rated by U.S adults $(n=1872)$ across six samples and two studies. Confirming preregistered hypotheses, there was a reliable preference for stories that were redeemed compared to stories that ended negatively, as well as for the narrators of redemptive stories, who were judged as likable and to have desirable personality traits. There was no support for the hypothesis that redemptive stories would be viewed as more common than non-redemptive stories, or that the relation between story type and preference would be mediated by Belief in a Just World. Implications include the compulsory nature of storying trauma and potential risks of these cultural expectations.
\end{abstract}

Key Words: redemption, narrative identity, master narratives, trauma 


\section{Redemptive Stories and Those Who Tell Them are Preferred in the U.S.}

The concept of redemption - when a challenging, negative, or traumatic experience is narrated in a way that communicates growth, meaning-made, or resolution - is perhaps the most commonly studied construct in the field of narrative identity (e.g., McAdams, 2006; McAdams \& McLean, 2013; McAdams \& Pals, 2006). This is for two primary reasons. First, it is a construct reliably associated with psychological health and well-being (see Adler, Lodi-Smith, Philippe, \& Houle, 2016 for a review). Second, it has such a strong relationship to the construction of personal identity narratives that it has been termed a cultural master narrative $-\mathrm{a}$ group-level narrative that guides personal story construction (Hammack, 2008; McAdams, 2006; McLean \& Syed, 2015). This means that there is a clear assumption that this story structure is a preferred story, or a 'good' story, at least within mainstream culture of the United States (U.S.). However, this claim, on which much of the extant empirical work rests, has yet to be tested. Testing that claim - that those in the U.S. prefer and positively evaluate redemptive stories and those who tell them - was the aim of the current project. Below we review the scholarship on redemption that guides the present endeavor.

\section{Preferred Stories: Redemption as a Cultural Master Narrative}

The concept of redemption as a master narrative is firmly rooted in an analysis of U.S. history and values (McAdams, 2006). Using cultural resources (e.g., movies, books) and historical documents (e.g., Gettysburg address, spiritual autobiographies, slave narratives, religious texts), McAdams (2006) has argued that those in the U.S. prefer redemptive stories due to their salience throughout U.S. history and the ways in which redemption reflects persistent values in the U.S., such as individualism, grit, and a 'bootstraps' mentality (see also McLean \& Syed, 2015). These stories of good persevering over evil, emancipation, and growth are believed 
to resonate with those in the U.S. - at least that is the pervasive claim (McAdams, 2006; 2008; McAdams \& McLean, 2013; McLean \& Syed, 2015).

The argument that redemption is a narrative that resonates with those in the U.S. is consistent with the notion that cultures communicate certain master narratives, which guide the individual's personal story construction. These master narratives dictate the kinds of stories that are valued and deemed appropriate for members of a particular culture to tell (McLean \& Syed, 2015). They are also viewed as culturally ubiquitous (McLean \& Syed, 2015), infusing narratives from movies to personal stories to historical documents, as McAdams (2006) has documented.

However, master narratives not only support and guide the construction of personal stories, they are also constraining in their prescription of the 'good' story (McLean \& Syed, 2015). This is particularly problematic for those whose stories do not align with these prescriptions. For example, those who do not tell culturally sanctioned stories may be disenfranchised, unheard, or marginalized (e.g., McLean, Lilgendahl, Fordham, Alpert, Marsden, Szymanowski, \& McAdams, 2017).

Experiencing trauma, an event that has the opportunity for narrative redemption, may pose special challenges to this prescription for redemption. By their very nature, traumatic events can be "unspeakable" in that they test the "just world" assumption that the world is a safe place where good things happen to good people (Furnham, 2003; see also Fivush, 2010). For the person who has experienced trauma, the possibility for a 'double trauma' exists with the coupling of the original experience and the potential for being unheard or rebuked if one's story is not redeemed. Further, an audience bearing witness to any traumatic story may experience distress, and a redemptive ending may restore the notion that the world is safe and that fair, 
resulting in a preference for such endings. Thus, understanding the degree to which redemptive stories are preferred may shed light on the role of interpersonal and cultural processes that may silence stories that do not align with this master narrative.

Preferred Storytellers: Evaluations of Redemptive Narrators

Substantial work has shown that those who tell more redemptive personal stories (compared to stories with negative endings) have better psychological functioning concurrently, and over time. For example, those with more redemptive stories are more likely to meet salient developmental tasks such as generativity (McAdams \& Guo, 2015) and identity formation (McLean \& Pratt, 2006). Those who narrate life story scenes with themes of redemption show increasing mental health after experiencing health challenges compared to those who do not (Adler et al., 2015). Those who made positive meaning of life low points experienced better emotion regulation two years later compared to those who did not (Cox \& McAdams, 2014). Finally, those who narrated the experience of their last drink with redemption were more likely to maintain sobriety over a subsequent four-month period (Dunlop \& Tracy, 2013). Based on this work (see Adler et al. 2014 for a comprehensive review), we expect that adults in the U.S. will evaluate the narrators of redemptive stories as higher functioning (e.g., psychologically healthier and happier) than the narrators of the same stories that end negatively. The implication of this is important given the interpersonal nature of storytelling - not telling the 'right' story could have serious interpersonal consequences.

Our approach is novel in that much of the prior work has evaluated whether personal stories are redemptive. However, in order to test the assumed preference for redemption, our questions centered not on individual storytellers, but on the evaluation of their stories.

\section{Present Studies}


Our aim was to examine whether there was empirical support for the pervasive assumption that redemption is a preferred structure for narrating trauma, a cultural master narrative. Using the master narrative framework, we hypothesized that redemption would manifest as the 'good' way to story trauma, such that stories and storytellers that align with the redemptive story structure will be evaluated more positively, and that such stories would also be viewed as common (McLean \& Syed, 2015).

We also examined one potential mechanism for this preference for redemption - Belief in a Just World (Furnham, 2003). Given the expectation that the world is fair and that good things happen to good people, traumatic events pose a challenge. The redemption of a trauma may preserve the sense that there is justice in the world because lemonade can come from lemons. In short, the preference for redemption may be driven in part by a desire to right an inexplicable wrong by employing a narrative strategy that restores order. We test this mediator using the measurement-of-mediator approach, which is fundamentally an observational analysis and thus speaks to statistical mediation vs. causal mediation (Bullock et al. 2010; Pirlott \& MacKinnon, 2016).

Given individual differences in the propensity to desire closure for negative events, and to experience and focus on negative affect, we considered Neuroticism and Need for Closure as control variables. We wanted to test whether story perceptions were consistently rated above and beyond these individual differences that may be related to emotional aspects of story perception (e.g., Lilgendahl \& McAdams, 2011; Lilgendahl \& McLean, 2019).

In a set of vignette-based studies, we tested the theoretical assumption that redemption is a preferred master narrative, taking several steps to examine this claim in breadth. First, as can be seen from the work described above, redemption has been shown to be important across a 
variety of types of life experiences, so we included multiple types of traumas. We constructed six different narratives of varied types of traumatic events that were acute and impersonal (natural disaster, car accident), chronic and impersonal (childhood chronic illness), chronic and personal (childhood sexual abuse), and acute and personal (adult sexual assault, traumatic loss). For each story we developed different types of endings. For example, we had an identical story about a car accident, but created different endings for that event. We take up the issue of the role of event type in more detail elsewhere (Delker, Salton, McLean, \& Syed, 2020), but here we expect the preference for redemptive stories, and their narrators, to be robust across types of trauma. Second, to determine the degree to which these preferences were robust across stories and participants we examined ratings both between-, and within-participants. Finally, we also recruited participants across a range of platforms in order to test the breadth of the effects.

Our hypotheses follow, and were pre-registered at https://osf.io/ter62/, where all materials, de-identified datasets, and scripts can be found.

H1. Story Preference. Participants will evaluate stories with redemptive endings to be more positive compared to stories with negative endings, even when controlling for constructs that might impact the desire for positive resolution, namely neuroticism and need for closure.

H2. Personal Preference. We expect stories with redemptive endings to be rated as more personally preferable overall compared to stories with negative endings.

H3. Narrative Ubiquity. Given claims that master narratives are in part defined by their ubiquity, we hypothesized that participants would rate stories with redemptive endings as more common than stories with negative endings.

H4. Narrator Preference. Participants will evaluate the 'narrators' of stories with redemptive endings more positively than the 'narrators' of stories with negative endings. 
H5. Belief in a Just World. The relation between story ending and story ratings will be mediated by Belief in a Just World.

The full details of our pilot study can be found at https://osf.io/ter62/. The aim of this study was to establish that the narratives we had created were evaluated as negative events, and that the endings were distinct. Participants rated six events in terms of the emotional valence of the overall event and the ending valence (negative, neutral, positive), and the degree to which it was redemptive. We tested six types of events (natural disaster, car accident, traumatic loss, stranger sexual assault, childhood sexual abuse, childhood chronic illness), and four different types of endings (negative, neutral, redemptive, survivor identity). For the purposes of another study we created two different types of redemptive endings - 'simple' redemption and what we

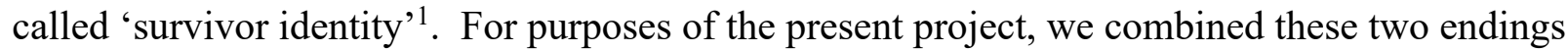
(see Delker et al., 2020) ${ }^{2}$. The events were all rated as negative, and the endings that we intended to be negative and redemptive were rated as expected. However, the stories we intended to be neutral in ending were much more variable, and were generally rated more negatively than anticipated. Thus, we proceeded with only testing the stories rated as negative and redemptive in their endings.

\section{Methods Studies 1 and 2}

Ethical review boards at two different institutions approved Studies 1 and 2 (Institutions and Protocol Numbers Masked for Blind Review).

\footnotetext{
${ }^{1}$ Please see our OSF page for a clear breakdown of the different variables used in each study, which asked fundamentally different questions about the perception of traumatic stories.

${ }^{2}$ Survivor endings were those that were redemptive, meaning there was positive resolution to the negative event, but they went a step further in that the narrator expressed positive resolution and integrated the event explicitly into their personal identity. For example, in the sexual assault narrative, the narrator became an advocate for other survivors. The examination of differences in survivor endings and the issue of personal/impersonal, acute/chronic is discussed elsewhere (Delker et al., 2019).
} 
We tested our hypotheses with a between-subjects (Study 1) and within-subjects (Study 2) design, using three samples per study ( $k=6$ samples total). The materials were identical for both Study 1 and Study 2, and for each sample, so we combine the methods and results of these two studies and six samples for efficiency.

\section{Participants}

See Table $1 \mathrm{a}-1 \mathrm{c}$ for participant characteristics $(n=1872)$ and exclusion numbers. We intentionally recruited from two quite different universities - both public, but differing in size and location (Pacific Northwest and upper Midwest) - as well as two different online platforms (Mturk - Study 1; Qualtrics - Study 2) in order to obtain a broad and diverse group of participants.

Table 1a. Demographic Characteristics of Study 1 Participants

\begin{tabular}{|c|c|c|c|c|}
\hline & $\begin{array}{l}\text { Total Sample } \\
(N=1,112)\end{array}$ & $\begin{array}{c}\text { MTurk } \\
(n=336)\end{array}$ & $\begin{array}{c}\text { University } 1 \\
(n=384)\end{array}$ & $\begin{array}{c}\text { University } 2 \\
(n=392)\end{array}$ \\
\hline Characteristic & $N(\%)$ & $n(\%)$ & $n(\%)$ & $n(\%)$ \\
\hline \multicolumn{5}{|l|}{ Gender } \\
\hline female & $706(63.5)$ & $181(53.9)$ & $268(70)$ & $257(65)$ \\
\hline male & $395(35.5)$ & $154(45.8)$ & $107(28)$ & $134(34)$ \\
\hline non-binary & $7(0.6)$ & NA & $7(0.02)$ & $0(0.0)$ \\
\hline transgender & $4(0.4)$ & $1(0.3)$ & $2(0.01)$ & $1(0.002)$ \\
\hline \multicolumn{5}{|l|}{ Race } \\
\hline White & 885 (73.7) & $275(81.8)$ & $317(73.5)$ & $293(70.3)$ \\
\hline Black & $68(5.7)$ & $32(9.5)$ & $12(2.8)$ & $24(5.8)$ \\
\hline Asian & $136(11.3)$ & $22(6.5)$ & $47(10.9)$ & $67(16.1)$ \\
\hline $\begin{array}{l}\text { Native Hawaiian / } \\
\text { Pacific Islander }\end{array}$ & $13(1.1)$ & $5(1.5)$ & $7(1.6)$ & $1(0.2)$ \\
\hline $\begin{array}{l}\text { Native American / } \\
\text { Alaska Native }\end{array}$ & $11(0.9)$ & $4(1.2)$ & $5(1.2)$ & $2(0.5)$ \\
\hline Latinx & $69(5.7)$ & $11(3.3)$ & $35(8.1)$ & $23(5.5)$ \\
\hline$* * * *$ & $19(1.6)$ & $4(1.2)$ & $8(1.9)$ & $7(1.7)$ \\
\hline \multirow[b]{2}{*}{ Age } & $M$ (range) & $M$ (range) & $M$ (range) & $M$ (range) \\
\hline & $26.99(18-71)$ & $\begin{array}{l}41.38(21- \\
71)\end{array}$ & $19.73(18-44)$ & $19.85(18-39)$ \\
\hline
\end{tabular}

Note. $* * * *$ denotes participants who provided a race not represented by the available categories, or two or more races. Total $n(\%)$ of race items do not add up to $100 \%$ because participants could select more than one. 
Table 1b. Demographic Characteristics of Study 2 Participants

\begin{tabular}{|c|c|c|c|c|}
\hline & $\begin{array}{l}\text { Total Sample } \\
(N=760)\end{array}$ & $\begin{array}{l}\text { Qualtrics } \\
(n=190)\end{array}$ & $\begin{array}{l}\text { University } 1 \\
(n=280)\end{array}$ & $\begin{array}{c}\text { University } 2 \\
(n=290)\end{array}$ \\
\hline Characteristic & $N(\%)$ & $n(\%)$ & $n(\%)$ & $n(\%)$ \\
\hline \multicolumn{5}{|l|}{ Gender } \\
\hline female & $574(75.8)$ & $148(78.3)$ & $229(81.8)$ & $197(68.4)$ \\
\hline male & $175(23.1)$ & $39(20.6)$ & $46(16.4)$ & $90(31.2)$ \\
\hline non-binary & $5(0.7)$ & NA & $4(1.4)$ & $1(0.3)$ \\
\hline transgender & $3(0.4)$ & $2(1.1)$ & $1(0.4)$ & $0(0.0)$ \\
\hline \multicolumn{5}{|l|}{ Race } \\
\hline White & $596(74.4)$ & $155(80.7)$ & $236(77.1)$ & $205(67.7)$ \\
\hline Black & $32(4.0)$ & $15(7.8)$ & $5(1.6)$ & $12(4.0)$ \\
\hline Asian & $104(13.0)$ & $7(3.6)$ & $30(9.8)$ & $67(22.1)$ \\
\hline $\begin{array}{l}\text { Native Hawaiian / } \\
\text { Pacific Islander }\end{array}$ & \multicolumn{4}{|c|}{ Native Hawaiian / } \\
\hline \multicolumn{5}{|l|}{ Native American / } \\
\hline Latinx & $44(5.5)$ & $9(4.7)$ & $24(7.8)$ & $11(3.6)$ \\
\hline$* * * *$ & $14(1.7)$ & $2(1.0)$ & $5(1.6)$ & $7(2.3)$ \\
\hline \multirow[b]{2}{*}{ Age } & $M$ (range) & $M$ (range) & $M$ (range) & $M$ (range) \\
\hline & $30.27(18-82)$ & $\begin{array}{l}50.89(18- \\
82)\end{array}$ & $20.08(17-67)$ & $19.85(18-39)$ \\
\hline
\end{tabular}

Note. $* * * *$ denotes participants who provided a race not represented by the available categories, or two or more races. Total $n(\%)$ of race items do not add up to $100 \%$ because participants could select more than one.

Table 1c. Reason for Excluding Cases from Analysis by Study and Site of Data Collection Study 1

\begin{tabular}{ccccccc} 
MTurk & University 1 & University 2 & & Qualtrics & University 1 & University 2 \\
\hline 475 & 432 & 461 & & 315 & 315 & 332 \\
\hline & & & & & & \\
\hline 15 & 37 & 64 & & 121 & 32 & 9 \\
103 & 14 & 21 & & 0 & 18 & 18 \\
97 & 6 & 23 & & 34 & 13 & 12 \\
7 & 13 & 5 & & 0 & 9 & $\mathbf{2 9 0}$ \\
$\mathbf{3 3 6}$ & $\mathbf{3 8 4}$ & $\mathbf{3 9 2}$ & & $\mathbf{1 9 0}$ & $\mathbf{2 8 0}$ & \\
\hline
\end{tabular}


Our decisions regarding sample size were based on our pilot data (see https://osf.io/ter62/), and the expectation of large effects due to the large differences between conditions and the high likelihood that they would be interpreted differently. The expectation of large effects was confirmed by the pilot study, and thus carried forward to the primary studies.

\section{Procedure and Design}

This survey-based study was administered online using Qualtrics and took approximately one hour to complete. Participants recruited through both MTurk and Qualtrics online panels self-selected to participate in the study titled "Evaluating Stories" for financial compensation upon the completion of the surveys, and if they passed the validity check questions.

Compensation was $\$ 2$ or $\$ 4$ on $\mathrm{Mturk}^{3}$, and was determined individually for each participant by Qualtrics for that panel. Students from the two universities were recruited through an undergraduate research pool, and were compensated with course credit. All participants provided informed consent electronically.

Participants evaluated the vignettes described in the pilot methods, followed by additional surveys, described below. Materials were identical for Studies 1 and 2, but the design differed. Study 1 was between-subjects design, with participants rating each of the six trauma vignettes with a randomized ending for each vignette. Study 2 was a within-subjects design, with participants rating all six trauma vignettes, but with only one ending type.

\section{Materials}

Vignettes and Evaluation. Participants read the six different vignettes described in the pilot methods with three different endings - negative, redemptive, survivor ending (with the latter two combined for analyses of effect sizes). Here we describe the ratings used to test our

\footnotetext{
${ }^{3}$ Per common rates, we initially paid participants $\$ 2$. However, we received a quite negative review of our payment, which essentially stopped all participation. Thus, we raised the payment to \$4.
} 
hypotheses. Full materials can be found at https://osf.io/ter62/, including the full set of items for the following scales (Table S1) and estimates of internal consistency for each scale by prompt and data set (Table S2).

Story Preference was assessed with one item to evaluate the valence: "How positive or negative was this event overall?" $(1=$ totally negative to $7=$ totally positive $)$.

Personal Preference was assessed with responses to four statements, such as, "I enjoyed reading this story" $(1=$ strongly disagree to $5=$ strongly agree; Cronbach's alphas $=.87-.95)$.

Narrative Ubiquity was assessed with responses to two statements regarding the commonality of the story, such as "This is a common story" $(1=$ strongly disagree to $5=$ strongly agree; Pearson's $r=.42-.72)$.

Narrator Preference was assessed with responses to five statements evaluating the author of the story, such as "I would like to get to know this author" $(1=$ strongly disagree to $5=$ strongly agree; Cronbach's alphas $=.68-.87)$. For an exploratory analysis, participants rated the 'narrators' of the stories for the Big Five traits, adapting the Ten-Item Personality Inventory (TIPI:Gosling, Rentfrow, \& Swann, 2003), with questions such as "This person is extraverted and enthusiastic" ( 1 = strongly disagree to $5=$ strongly agree). Two items were rated for each of the Big Five traits (extraversion, emotional stability, agreeableness, conscientiousness, openness), with one positive item and one negative item for each scale (items and reliabilities reported in Tables S1 and S2).

Control Variables: Neuroticism and Need for Closure. Following ratings of the vignettes, participants completed two control measures. Participants completed the Big Five Inventory-2, a 60-item measure of personality traits (Soto \& John, 2017), using a five-point scale ( 1 = disagree strongly to 5 = agree strongly). The 12-item neuroticism subscale was used as a control measure 
$($ Cronbach's alphas $=.85-94)$. Additionally, participants completed the 15 -item Need for Closure scale (Roets \& Van Hiel, 2011; $1=$ strongly disagree to $6=$ strongly agree; Cronbach's alphas $=.83-92)$.

Mediator: Belief in a Just World. Participants also completed an eight-item measure of Belief in a Just World (Lucas, Zhdanova, \& Alexander, 2011; $1=$ strongly disagree to $7=$ strongly agree; Cronbach's alphas $=.89-96)$.

The final block of questions included demographics.

\section{Results}

\section{Analysis Plan}

All analyses were conducted separately for each of the six event types within each of the six samples. This led to 18 individual tests of each hypothesis within each study, conducted via ANOVAs in SPSS v. 24.0 (IBM Corp, 2016; more details below for each test). The assessment of the support for the hypotheses was determined based on the meta-analytic summary of the 18 tests within each study. Cohen's $d$ was calculated for the mean difference between the redemptive endings and the negative endings for each event type in R 3.6.1 (R Core Team, 2019) with the MBESS package (v.4.6.0, Kelley, 2019). These $d$ s were subject to the meta-analysis to determine an estimate and range that was used to evaluate the hypothesis. Thus, although there are numerous individual tests of each hypothesis, only the two meta-analytic estimates were used for evaluating the hypotheses (one for each study). $95 \%$ confidence intervals are reported with each test to provide an indicator of precision of the effect size estimate. The meta-analyses were conducted using the R package metafor (v.2.1, Viechtbauer, 2010). We had preregistered that we would use a fixed effects meta-analysis because all of the studies represented a test of the hypothesis from the same population and we did not seek to test for moderators. However, 
instead we report analyses of multi-level random effects meta-analyses in order to account for the dependencies among the effects sizes. The point estimates are nearly identical using both methods, but the confidence intervals are wider in the random effects models. Results from the fixed effects models are available on the OSF page. Forest plots were created using the R package ggplot2 (v.3.2.0, Wickham 2016). Although the purpose of the present study was not to investigate variations in effect sizes across the different samples or story prompts, in Table S3 we report indices of heterogeneity $\left(\mathrm{Q}, \mathrm{I}^{2}\right.$, and tau) for the curious reader. All primary analyses were preregistered on OSF. Any exploratory analysis that was not preregistered is marked as such in the text below. Means, standard deviations, and correlations for all variables and data sets are available in Table S4.

\section{Hypothesis 1. Story Preference: Stories that are redemptive will be rated more} positively compared to stories with negative endings.

Study 1. This hypothesis was tested via one-way between-subjects ANOVAs, each examining mean differences in positive story ratings for the six event types. Results clearly indicated substantial mean differences in positivity ratings between redemptive/survivor vs. negative endings ${ }^{4}$, with all 18 effect sizes exceeding $d=1.0$ (see Table 2, Figure 1). Indeed, the meta-analytic test provided strong support for the hypothesis, $d=1.83,(1.59,2.08)$.

Table 2. Descriptive Statistics and Effect Sizes for Study 1 Hypothesis 1: Differences in Positivity Ratings

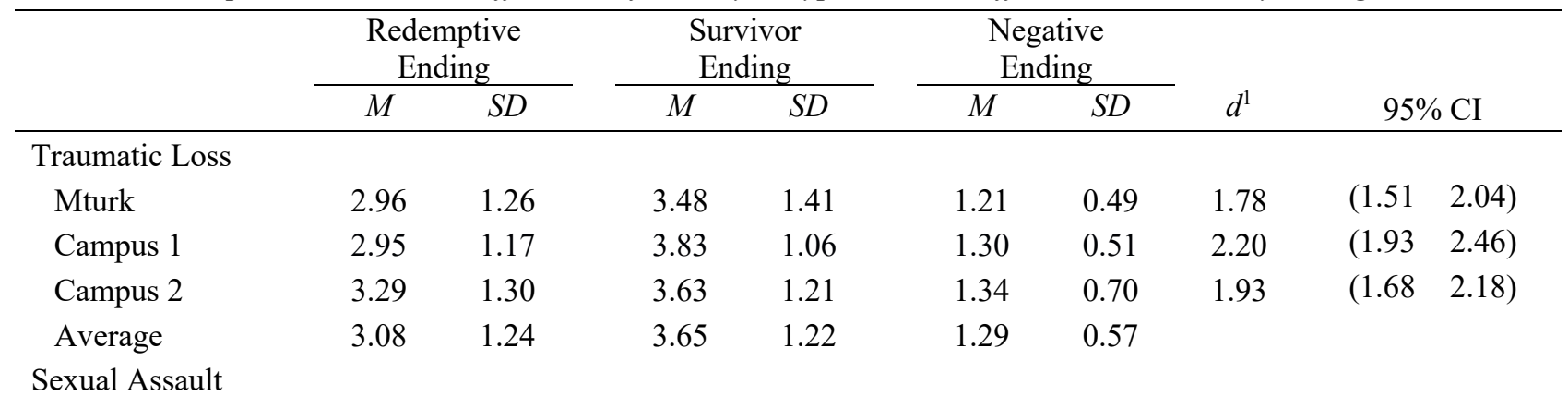

\footnotetext{
${ }^{4}$ For clarity, we report the statistics separately for redemptive and survivor endings in our table.
} 
Preferences for Redemption 15

$\begin{array}{llllllllll}\text { Mturk } & 2.10 & 1.16 & 2.68 & 1.40 & 1.24 & 0.68 & 1.03 & (0.80 & 1.27) \\ \text { Campus 1 } & 2.91 & 1.51 & 3.21 & 1.31 & 1.26 & 0.75 & 1.45 & (1.22 & 1.69) \\ \text { Campus 2 } & 2.82 & 1.35 & 3.15 & 1.33 & 1.14 & 0.37 & 1.64 & (1.39 & 1.88) \\ \quad \text { Average } & 2.64 & 1.35 & 3.03 & 1.34 & 1.21 & 0.60 & & & \\ \text { Car Accident } & & & & & & & & & \\ \text { Mturk } & 4.04 & 1.47 & 4.32 & 1.41 & 1.77 & 1.12 & 1.79 & (1.53 & 2.05) \\ \text { Campus 1 } & 4.55 & 1.20 & 4.59 & 1.27 & 1.70 & 0.90 & 2.54 & (2.26 & 2.82) \\ \text { Campus 2 } & 4.28 & 1.26 & 4.65 & 1.10 & 1.89 & 0.96 & 2.31 & (2.05 & 2.58) \\ \text { Average } & 4.30 & 1.30 & 4.53 & 1.25 & 1.79 & 0.99 & & & \\ \text { Hurricane } & & & & & & & & & \\ \text { Mturk } & 4.11 & 1.50 & 3.70 & 1.49 & 1.47 & 0.77 & 1.89 & (1.62 & 2.15) \\ \text { Campus 1 } & 4.21 & 1.29 & 3.97 & 1.30 & 1.60 & 0.83 & 1.80 & (1.55 & 2.04) \\ \text { Campus 2 } & 4.35 & 1.21 & 3.73 & 1.31 & 1.54 & 0.85 & 2.18 & (1.92 & 2.44) \\ \text { Average } & 4.23 & 1.33 & 3.81 & 1.36 & 1.54 & 0.82 & & & \\ \text { Child Sexual Abuse } & & & & & & & & & \\ \text { Mturk } & 2.88 & 1.57 & 3.17 & 1.53 & 1.33 & 0.82 & 1.26 & (1.01 & 1.50) \\ \text { Campus 1 } & 3.46 & 1.42 & 3.84 & 1.32 & 1.47 & 0.80 & 1.80 & (1.55 & 2.05) \\ \text { Campus 2 } & 3.21 & 1.38 & 3.40 & 1.37 & 1.36 & 0.71 & 1.64 & (1.40 & 1.87) \\ \text { Average } & 3.20 & 1.45 & 3.49 & 1.40 & 1.39 & 0.77 & & & \\ \text { Childhood Chronic } & & & & & & & & & \end{array}$

${ }^{1}$ Cohen's d based on comparison of the combined Redemptive/Survivor endings to the Negative endings. 


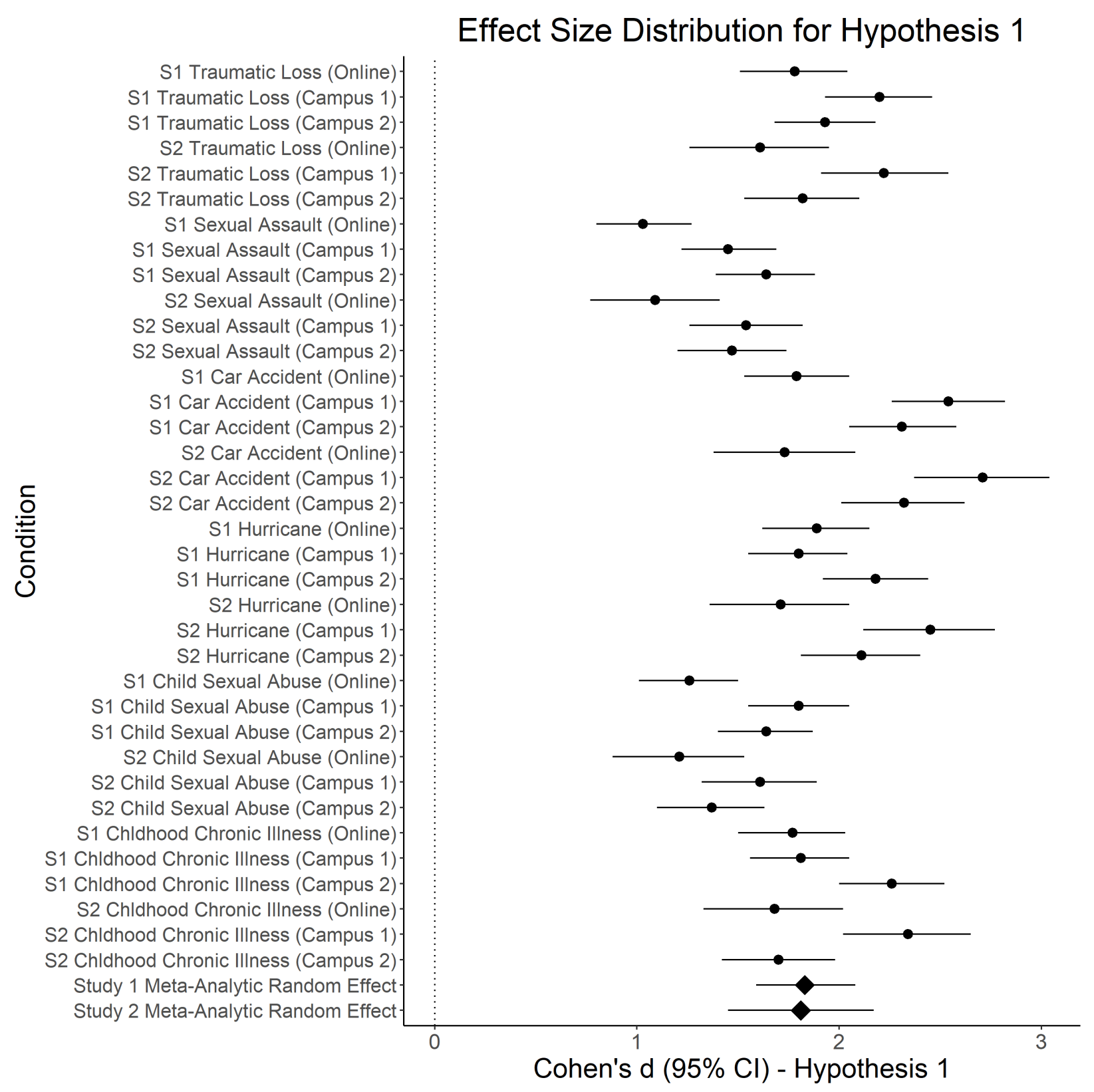

Figure 1. Forest plot for Hypothesis 1

Hypothesis 1a stated that the difference observed in Hypothesis 1 would remain after controlling for neuroticism and need for closure. This hypothesis was supported, with the effect sizes virtually unchanged by the inclusion of these covariates (Table S5). 
Study 2. Hypothesis 1 in Study 2 was tested by a 3 (ending) x 6 (event) mixed ANOVA with ending as the between-subjects factor and event as the repeated within-subjects factor. Positivity ratings of the stories was the dependent variable. For this hypothesis the betweensubjects main effect was the target analysis; specifically, the between-subjects contrast between redemptive/survivor endings and negative endings. Consistent with Study 2, the meta-analytic effect size across the 18 effects indicated strong support for the hypothesis, $d=1.81,(1.45,2.12)$ (Table 3 and Figure 1). Moreover, controlling for neuroticism and need for closure did not alter the effects (Table S5).

Table 3

Descriptive Statistics and Effect Sizes for Study 2 Hypothesis 1: Differences in Positivity Ratings

\begin{tabular}{|c|c|c|c|c|c|c|c|c|c|}
\hline & \multicolumn{2}{|c|}{$\begin{array}{c}\text { Redemptive } \\
\text { Ending }\end{array}$} & \multicolumn{2}{|c|}{$\begin{array}{l}\text { Survivor } \\
\text { Ending }\end{array}$} & \multicolumn{2}{|c|}{$\begin{array}{l}\text { Negative } \\
\text { Ending }\end{array}$} & \multirow[b]{2}{*}{$d^{1}$} & \multirow{2}{*}{\multicolumn{2}{|c|}{$95 \% \mathrm{CI}$}} \\
\hline & $M$ & $S D$ & $M$ & $S D$ & $M$ & $S D$ & & & \\
\hline \multicolumn{10}{|c|}{ Traumatic Loss } \\
\hline Qualtrics & 4.28 & 1.94 & 5.08 & 1.67 & 1.84 & 1.55 & 1.61 & $(1.26$ & 1.95) \\
\hline Campus 1 & 3.22 & 1.20 & 3.83 & 1.11 & 1.25 & 0.49 & 2.22 & $(1.91$ & $2.54)$ \\
\hline Campus 2 & 2.87 & 1.19 & 3.63 & 1.19 & 1.32 & 0.57 & 1.82 & $(1.53$ & $2.10)$ \\
\hline Average & 3.36 & 1.39 & 4.06 & 1.27 & 1.43 & 0.79 & & & \\
\hline \multicolumn{10}{|c|}{ Sexual Assault } \\
\hline Qualtrics & 3.23 & 1.88 & 4.02 & 1.67 & 1.71 & 1.56 & 1.09 & $(0.77$ & $1.41)$ \\
\hline Campus 1 & 2.86 & 1.42 & 3.12 & 1.27 & 1.22 & 0.52 & 1.54 & $(1.26$ & 1.82) \\
\hline Campus 2 & 2.74 & 1.37 & 3.18 & 1.38 & 1.25 & 0.52 & 1.47 & $(1.20$ & $1.74)$ \\
\hline Average & 2.91 & 1.52 & 3.36 & 1.41 & 1.36 & 0.78 & & & \\
\hline \multicolumn{10}{|l|}{ Car Accident } \\
\hline Qualtrics & 4.91 & 1.62 & 4.79 & 1.64 & 2.06 & 1.59 & 1.73 & $(1.38$ & 2.08) \\
\hline Campus 1 & 4.61 & 1.30 & 4.66 & 1.04 & 1.74 & 0.81 & 2.71 & $(2.37$ & $3.04)$ \\
\hline Campus 2 & 4.50 & 1.29 & 4.67 & 1.10 & 2.00 & 0.93 & 2.32 & $(2.01$ & 2.62) \\
\hline Average & 4.65 & 1.38 & 4.69 & 1.21 & 1.92 & 1.05 & & & \\
\hline \multicolumn{10}{|l|}{ Hurricane } \\
\hline Qualtrics & 5.31 & 1.53 & 4.53 & 1.73 & 2.14 & 1.55 & 1.71 & $(1.36$ & $2.05)$ \\
\hline Campus 1 & 4.49 & 1.30 & 3.89 & 1.27 & 1.39 & 0.58 & 2.45 & $(2.12$ & $2.77)$ \\
\hline Campus 2 & 4.43 & 1.33 & 4.16 & 1.27 & 1.78 & 0.94 & 2.11 & $(1.81$ & $2.40)$ \\
\hline Average & 4.68 & 1.37 & 4.14 & 1.38 & 1.74 & 0.97 & & & \\
\hline \multicolumn{10}{|c|}{ Child Sexual Abuse } \\
\hline Qualtrics & 3.83 & 2.00 & 4.35 & 1.94 & 1.84 & 1.58 & 1.21 & $(0.88$ & $1.53)$ \\
\hline Campus 1 & 3.28 & 1.35 & 3.45 & 1.42 & 1.41 & 0.71 & 1.61 & $(1.32$ & 1.89) \\
\hline Campus 2 & 3.12 & 1.49 & 3.48 & 1.44 & 1.51 & 0.93 & 1.37 & $(1.10$ & 1.63) \\
\hline Average & 3.36 & 1.57 & 3.68 & 1.55 & 1.56 & 1.02 & & & \\
\hline
\end{tabular}


Childhood Chronic

Illness

\begin{tabular}{llllllllll} 
Qualtrics & 4.88 & 1.88 & 5.15 & 1.61 & 2.16 & 1.59 & 1.68 & $(1.33$ & $2.02)$ \\
Campus 1 & 4.32 & 1.24 & 4.48 & 1.34 & 1.67 & 0.84 & 2.34 & $(2.02$ & $2.65)$ \\
Campus 2 & 3.90 & 1.39 & 4.81 & 1.16 & 2.20 & 1.10 & 1.70 & $(1.42$ & $1.98)$ \\
Average & 4.31 & 1.46 & 4.76 & 1.34 & 2.01 & 1.13 & & & \\
\hline
\end{tabular}

${ }^{1}$ Cohen's d based on comparison of the combined Redemptive/Survivor endings to the Negative endings.

Hypothesis 2. Personal Preference: Stories with redemptive endings will be rated as more personally preferable compared to stories with negative endings.

Study 1. This hypothesis was tested via one-way between-subjects ANOVAs, each examining mean differences in personal preference ratings for the six event types. Again, effect sizes were large and consistent, with the meta-analytic estimate providing strong support for the hypothesis, $d=1.62(1.34,1.90)$ (Table 4 and Figure 2).

Table 4

Descriptive Statistics and Effect Sizes for Study 1 Hypothesis 2: Differences in Personal Story Preference

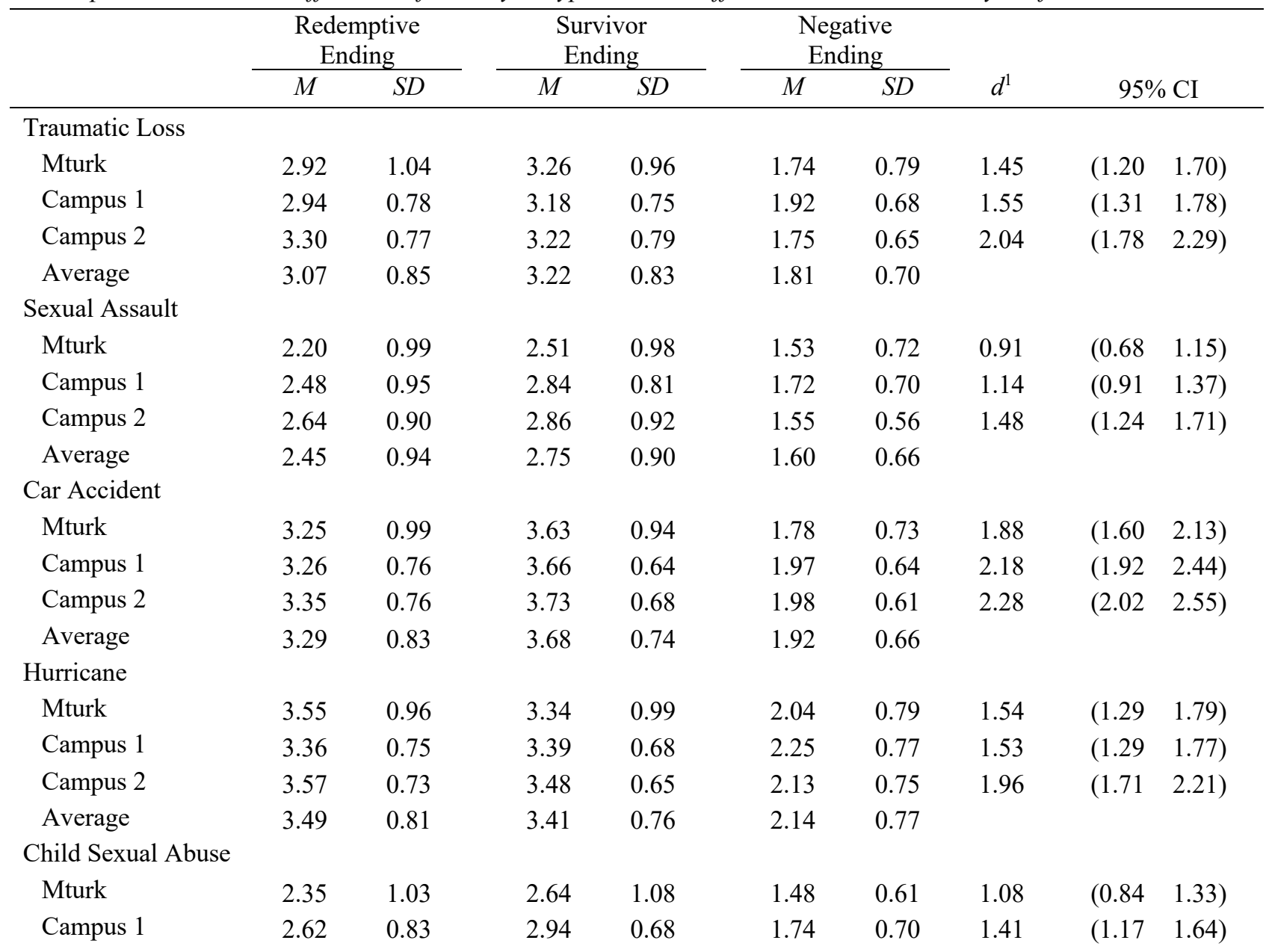


Preferences for Redemption 19

\begin{tabular}{llllllllll} 
Campus 2 & 2.56 & 0.91 & 2.79 & 0.86 & 1.60 & 0.70 & 1.30 & $(1.07$ & $1.53)$ \\
$\quad \begin{array}{l}\text { Average } \\
\text { Childhood Chronic }\end{array}$ & 2.52 & 0.92 & 2.80 & 0.86 & 1.61 & 0.67 & & & \\
$\begin{array}{l}\text { Illness } \\
\quad \text { Mturk }\end{array}$ & & & & & & & & & \\
$\quad$ Campus 1 & 3.63 & 0.85 & 3.95 & 0.86 & 2.22 & 1.04 & 1.70 & $(1.44$ & $1.96)$ \\
Campus 2 & 3.38 & 0.69 & 3.72 & 0.75 & 2.47 & 0.73 & 1.49 & $(1.25$ & $1.72)$ \\
Average & 3.66 & 0.68 & 3.99 & 0.61 & 2.22 & 0.73 & 2.38 & $(2.12$ & $2.65)$ \\
\hline
\end{tabular}

${ }^{1}$ Cohen's d based on comparison of the combined Redemptive/Survivor endings to the Negative endings.

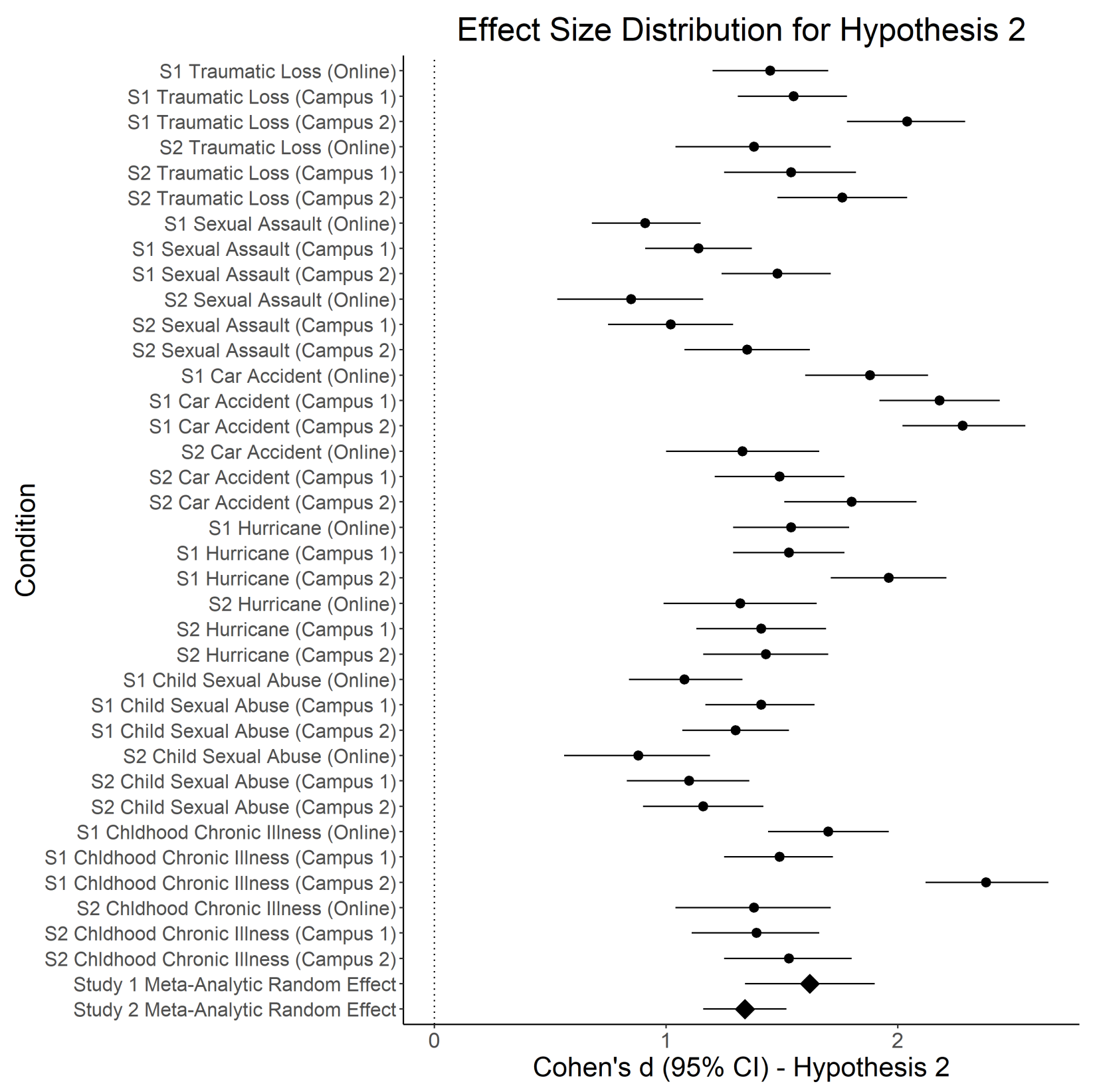

Figure 2. Forest plot for Hypothesis 2 
Study 2. This hypothesis was tested by a 3 (ending) x 6 (event) mixed ANOVA with ending as the between-subjects factor and event as the repeated within-subjects factor. Personal preference ratings of the stories was the dependent variable, with the between-subjects contrast between redemptive/survivor endings and negative endings as the focal analysis. Consistent with Study 1 , the meta-analytic effect size indicated strong support for the hypothesis, $d=1.34(1.16$, 1.52) (Table 5 and Figure 2).

Table 5

Descriptive Statistics and Effect Sizes for Study 2 Hypothesis 2: Differences in Personal Story Preference

\begin{tabular}{|c|c|c|c|c|c|c|c|c|c|}
\hline \multirow{3}{*}{$\begin{array}{l}\text { Traumatic Lo } \\
\end{array}$} & \multicolumn{2}{|c|}{$\begin{array}{l}\text { Redemptive } \\
\text { Ending }\end{array}$} & \multicolumn{2}{|c|}{$\begin{array}{c}\text { Survivor } \\
\text { Ending }\end{array}$} & \multicolumn{2}{|c|}{$\begin{array}{l}\text { Negative } \\
\text { Ending }\end{array}$} & \multirow[b]{2}{*}{$d^{1}$} & \multirow{2}{*}{\multicolumn{2}{|c|}{$95 \%$ CI }} \\
\hline & \multirow[t]{2}{*}{$M$} & \multirow[t]{2}{*}{$S D$} & \multirow[t]{2}{*}{$M$} & \multirow[t]{2}{*}{$S D$} & \multirow[t]{2}{*}{$M$} & \multirow[t]{2}{*}{$S D$} & & & \\
\hline & & & & & & & 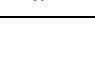 & \multicolumn{2}{|c|}{ 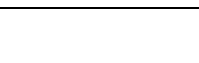 } \\
\hline Qualtrics & 3.39 & 0.98 & 3.52 & 0.80 & 2.13 & 1.12 & 1.38 & $(1.04$ & 1.71) \\
\hline Campus 1 & 3.07 & 0.82 & 3.14 & 0.74 & 1.95 & 0.68 & 1.54 & $(1.25$ & 1.82) \\
\hline Campus 2 & 2.98 & 0.81 & 3.21 & 0.78 & 1.78 & 0.62 & 1.76 & $(1.48$ & 2.04) \\
\hline Average & 3.12 & 0.86 & 3.26 & 0.77 & 1.93 & 0.77 & & & \\
\hline \multicolumn{10}{|c|}{ Sexual Assault } \\
\hline Qualtrics & 2.63 & 1.00 & 2.91 & 1.05 & 1.89 & 1.04 & 0.85 & $(0.53$ & 1.16) \\
\hline Campus 1 & 2.50 & 0.90 & 2.68 & 0.89 & 1.72 & 0.71 & 1.02 & $(0.75$ & 1.29) \\
\hline Campus 2 & 2.53 & 0.93 & 2.79 & 0.86 & 1.57 & 0.59 & 1.35 & $(1.08$ & 1.62) \\
\hline Average & 2.54 & 0.94 & 2.78 & 0.92 & 1.70 & 0.75 & & & \\
\hline \multicolumn{10}{|l|}{ Car Accident } \\
\hline Qualtrics & 3.39 & 0.84 & 3.44 & 0.88 & 2.19 & 1.04 & 1.33 & $(1.00$ & 1.66) \\
\hline Campus 1 & 3.20 & 0.71 & 3.24 & 0.87 & 2.09 & 0.67 & 1.49 & $(1.21$ & 1.77) \\
\hline Campus 2 & 3.24 & 0.77 & 3.30 & 0.76 & 1.96 & 0.66 & 1.80 & $(1.51$ & 2.08) \\
\hline Average & 3.26 & 0.77 & 3.31 & 0.83 & 2.06 & 0.76 & & & \\
\hline \multicolumn{10}{|l|}{ Hurricane } \\
\hline Qualtrics & 3.77 & 0.81 & 3.35 & 0.84 & 2.29 & 1.09 & 1.32 & $(0.99$ & $1.65)$ \\
\hline Campus 1 & 3.42 & 0.64 & 3.10 & 0.76 & 2.21 & 0.76 & 1.41 & $(1.13$ & $1.69)$ \\
\hline Campus 2 & 2.21 & 0.79 & 3.47 & 0.74 & 3.17 & 0.77 & 1.43 & $(1.16$ & 1.70) \\
\hline Average & 3.06 & 0.74 & 3.30 & 0.77 & 2.61 & 0.85 & & & \\
\hline \multicolumn{10}{|c|}{ Child Sexual Abuse } \\
\hline Qualtrics & 2.63 & 1.11 & 2.91 & 1.03 & 1.83 & 1.03 & 0.88 & $(0.56$ & $1.19)$ \\
\hline Campus 1 & 2.48 & 0.90 & 2.74 & 0.89 & 1.68 & 0.72 & 1.10 & $(0.83$ & 1.36) \\
\hline Campus 2 & 2.50 & 0.90 & 2.77 & 0.94 & 1.64 & 0.70 & 1.16 & $(0.90$ & 1.42) \\
\hline Average & 2.53 & 0.95 & 2.79 & 0.94 & 1.70 & 0.79 & & & \\
\hline \multicolumn{10}{|c|}{$\begin{array}{l}\text { Childhood Chronic } \\
\text { Illness }\end{array}$} \\
\hline Qualtrics & 3.50 & 0.86 & 3.77 & 0.68 & 2.36 & 1.14 & 1.38 & $(1.04$ & $1.71)$ \\
\hline Campus 1 & 3.39 & 0.76 & 3.60 & 0.81 & 2.38 & 0.85 & 1.39 & $(1.11$ & 1.66) \\
\hline Campus 2 & 3.50 & 0.75 & 3.87 & 0.67 & 2.42 & 0.98 & 1.53 & $(1.25$ & $1.80)$ \\
\hline
\end{tabular}


$\begin{array}{lllllll}\text { Average } & 3.46 & 0.78 & 3.74 & 0.73 & 2.39 & 0.98\end{array}$

${ }^{1}$ Cohen's d based on comparison of the combined Redemptive/Survivor endings to the Negative endings.

\section{Hypothesis 3. Narrative Ubiquity: Redemptive stories will be rated as more} common and frequently heard compared to stories with negative endings.

Study 1. This hypothesis was tested via one-way between-subjects ANOVAs, each examining mean differences in perceived commonality ratings for the six event types. Effect sizes were generally uniformly small and danced around either side of zero. Consistent with this, the meta-analytic estimate did not provide support for the hypothesis, $d=-0.01(-0.11,0.08)$ (Table 6 and Figure 3).

Table 6

Descriptive Statistics and Effect Sizes for Study 1 Hypothesis 3: Differences in Narrative Ubiquity

\begin{tabular}{|c|c|c|c|c|c|c|c|c|c|}
\hline \multirow{3}{*}{$\begin{array}{l}\text { Traumatic Lo } \\
\end{array}$} & \multicolumn{2}{|c|}{$\begin{array}{l}\text { Redemptive } \\
\text { Ending }\end{array}$} & \multicolumn{2}{|c|}{$\begin{array}{c}\text { Survivor } \\
\text { Ending }\end{array}$} & \multicolumn{2}{|c|}{$\begin{array}{l}\text { Negative } \\
\text { Ending }\end{array}$} & \multirow[b]{2}{*}{$d^{1}$} & \multirow{2}{*}{\multicolumn{2}{|c|}{$95 \% \mathrm{CI}$}} \\
\hline & \multirow[t]{2}{*}{$M$} & \multirow[t]{2}{*}{$S D$} & \multirow[t]{2}{*}{$M$} & \multirow[t]{2}{*}{$S D$} & \multirow[t]{2}{*}{$M$} & \multirow[t]{2}{*}{$S D$} & & & \\
\hline & & & & & & & & & \\
\hline Mturk & 3.10 & 0.74 & 3.12 & 0.92 & 2.88 & 0.85 & 0.27 & $(0.04$ & $0.50)$ \\
\hline Campus 1 & 3.58 & 0.84 & 3.62 & 0.81 & 3.66 & 0.69 & 0.08 & $(-0.13$ & $0.29)$ \\
\hline Campus 2 & 3.44 & 0.85 & 3.43 & 0.78 & 3.27 & 0.85 & 0.20 & $(-0.01$ & $0.41)$ \\
\hline Average & 3.39 & 0.82 & 3.40 & 0.84 & 3.29 & 0.79 & & & \\
\hline \multicolumn{10}{|c|}{ Sexual Assault } \\
\hline Mturk & 3.73 & 0.87 & 3.73 & 0.79 & 3.55 & 1.03 & 0.19 & $(-0.03$ & $0.42)$ \\
\hline Campus 1 & 3.97 & 0.79 & 4.02 & 0.66 & 4.10 & 0.75 & -0.14 & $(-0.36$ & $0.07)$ \\
\hline Campus 2 & 3.80 & 0.86 & 3.83 & 0.77 & 3.96 & 0.75 & -0.18 & $(-0.40$ & $0.03)$ \\
\hline Average & 3.84 & 0.84 & 3.87 & 0.74 & 3.88 & 0.84 & & & \\
\hline \multicolumn{10}{|l|}{ Car Accident } \\
\hline Mturk & 3.73 & 0.82 & 2.91 & 1.07 & 3.51 & 0.89 & -0.21 & $(-0.44$ & $0.02)$ \\
\hline Campus 1 & 3.78 & 0.75 & 3.44 & 0.81 & 3.62 & 0.79 & -0.07 & $(-0.28$ & $0.15)$ \\
\hline Campus 2 & 3.78 & 0.79 & 3.27 & 0.81 & 3.60 & 0.89 & -0.09 & $(-0.30$ & $0.12)$ \\
\hline Average & 3.76 & 0.79 & 3.22 & 0.89 & 3.58 & 0.86 & & & \\
\hline \multicolumn{10}{|l|}{ Hurricane } \\
\hline Mturk & 3.46 & 0.88 & 3.04 & 0.95 & 3.48 & 0.91 & -0.25 & $(-0.48$ & $-0.03)$ \\
\hline Campus 1 & 3.32 & 0.92 & 3.20 & 0.82 & 3.33 & 0.87 & -0.08 & $(-0.29$ & $0.13)$ \\
\hline Campus 2 & 3.16 & 0.83 & 3.13 & 0.83 & 3.43 & 0.88 & -0.34 & $(-0.55$ & $-0.12)$ \\
\hline Average & 3.31 & 0.88 & 3.13 & 0.86 & 3.41 & 0.89 & & & \\
\hline \multicolumn{10}{|c|}{ Child Sexual Abuse } \\
\hline Mturk & 3.42 & 0.89 & 3.23 & 0.96 & 3.45 & 0.97 & -0.13 & $(-0.35$ & $0.10)$ \\
\hline Campus 1 & 3.46 & 0.82 & 3.52 & 0.88 & 3.71 & 0.79 & -0.26 & $(-0.48$ & $-0.05)$ \\
\hline
\end{tabular}


Preferences for Redemption 22

\begin{tabular}{lcccccccccc} 
Campus 2 & 3.30 & 0.96 & 3.31 & 0.87 & 3.23 & 0.87 & 0.08 & $(-0.12$ & $0.29)$ \\
$\quad$ Average & 3.39 & 0.89 & 3.36 & 0.90 & 3.46 & 0.87 & & & \\
$\begin{array}{l}\text { Childhood Chronic } \\
\text { Illness }\end{array}$ & & & & & & & & & \\
$\quad$ Mturk & 3.20 & 0.92 & 2.85 & 0.94 & 2.89 & 0.99 & 0.14 & $(-0.08$ & $0.37)$ \\
Campus 1 & 3.22 & 0.86 & 3.20 & 0.88 & 3.14 & 0.88 & 0.08 & $(-0.12$ & $0.29)$ \\
Campus 2 & 3.41 & 0.78 & 3.10 & 0.88 & 2.88 & 0.94 & 0.43 & $(0.21$ & $0.64)$ \\
Average & 3.28 & 0.85 & 3.07 & 0.90 & 2.98 & 0.93 & & & \\
\hline
\end{tabular}

${ }^{1}$ Cohen's d based on comparison of the combined Redemptive/Survivor endings to the Negative endings.

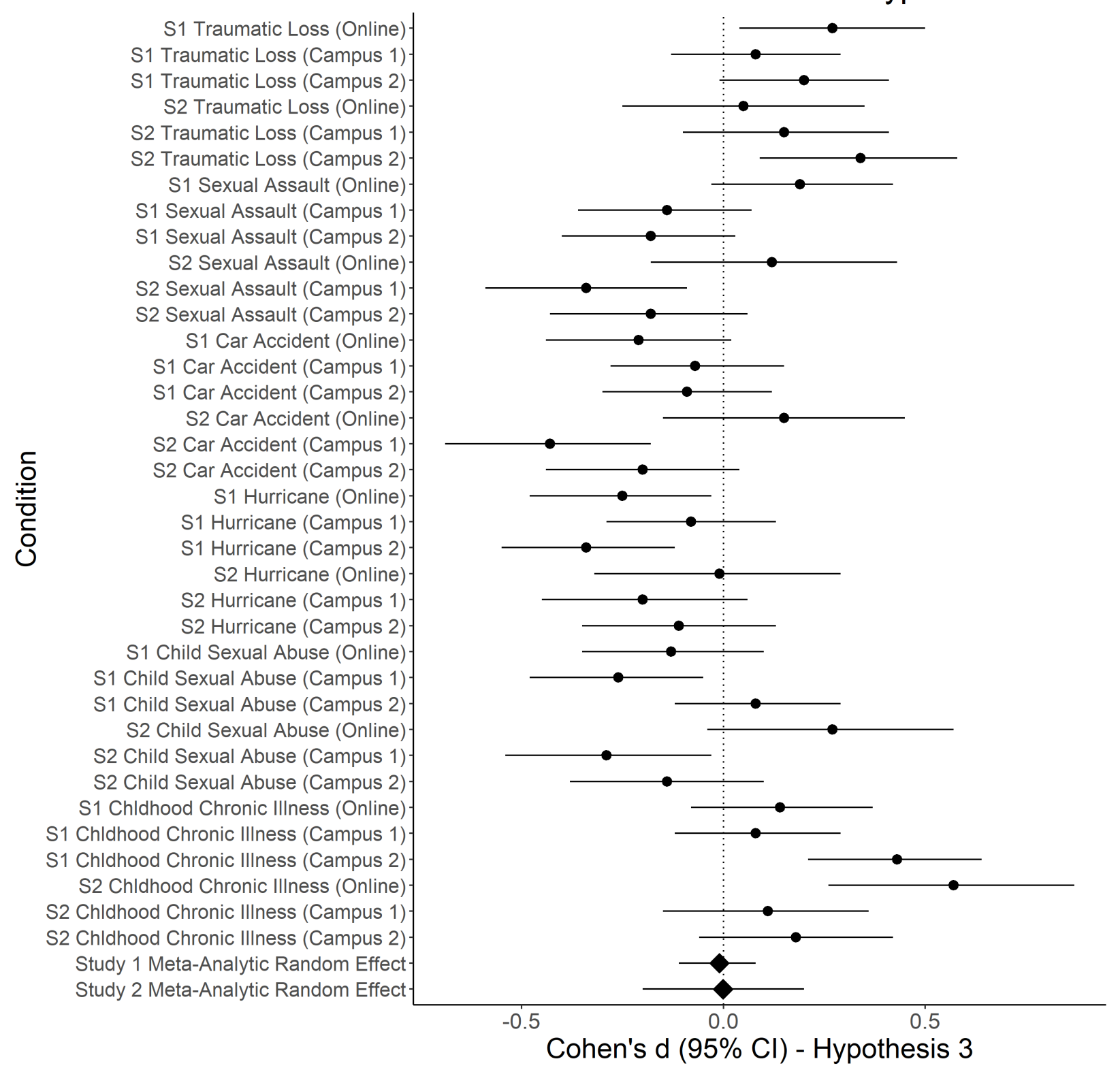

Figure 3. Forest plot for Hypothesis 3 
Study 2. This hypothesis was tested by a 3 (ending) x 6 (event) mixed ANOVA with ending as the between-subjects factor and event as the repeated within-subjects factor. Perceived commonality ratings of the stories was the dependent variable, with the between-subjects contrast between redemptive/survivor endings and negative endings as the focal analysis. Results mirrored Study 1, indicating no support for the hypothesis, $d=-0.001(-0.20,0.20)$ (Table 7 and Figure 3).

Table 7

Descriptive Statistics and Effect Sizes for Study 2 Hypothesis 3: Differences in Narrative Ubiquity

\begin{tabular}{|c|c|c|c|c|c|c|c|c|c|}
\hline & \multicolumn{2}{|c|}{$\begin{array}{l}\text { Redemptive } \\
\text { Ending }\end{array}$} & \multicolumn{2}{|c|}{$\begin{array}{l}\text { Survivor } \\
\text { Ending }\end{array}$} & \multicolumn{2}{|c|}{$\begin{array}{l}\text { Negative } \\
\text { Ending }\end{array}$} & \multirow[b]{2}{*}{$d^{1}$} & \multirow{2}{*}{\multicolumn{2}{|c|}{$95 \% \mathrm{CI}$}} \\
\hline & $M$ & $S D$ & $M$ & $S D$ & $M$ & $S D$ & & & \\
\hline \multicolumn{10}{|c|}{ Traumatic Loss } \\
\hline Qualtrics & 3.42 & 0.92 & 3.40 & 0.95 & 3.37 & 1.02 & 0.05 & $(-0.25$ & $0.35)$ \\
\hline Campus 1 & 3.61 & 0.76 & 3.76 & 0.68 & 3.57 & 0.78 & 0.15 & $(-0.10$ & $0.41)$ \\
\hline Campus 2 & 3.54 & 0.79 & 3.52 & 0.81 & 3.23 & 1.04 & 0.34 & $(0.09$ & $0.58)$ \\
\hline Average & 3.53 & 0.81 & 3.58 & 0.79 & 3.38 & 0.94 & & & \\
\hline \multicolumn{10}{|c|}{ Sexual Assault } \\
\hline Qualtrics & 3.69 & 0.93 & 3.79 & 0.78 & 3.63 & 1.02 & 0.12 & $(-0.18$ & $0.43)$ \\
\hline Campus 1 & 4.03 & 0.76 & 3.97 & 0.68 & 4.24 & 0.64 & -0.34 & $(-0.59$ & $-0.09)$ \\
\hline Campus 2 & 4.19 & 0.69 & 3.99 & 0.76 & 4.09 & 0.84 & -0.18 & $(-0.43$ & $0.06)$ \\
\hline Average & 4.00 & 0.78 & 3.93 & 0.73 & 4.03 & 0.82 & & & \\
\hline \multicolumn{10}{|l|}{ Car Accident } \\
\hline Qualtrics & 3.69 & 0.92 & 3.36 & 1.00 & 3.39 & 0.96 & 0.15 & $(-0.15$ & $0.45)$ \\
\hline Campus 1 & 3.78 & 0.76 & 3.36 & 0.88 & 3.91 & 0.64 & -0.43 & $(-0.69$ & $-0.18)$ \\
\hline Campus 2 & 3.87 & 0.73 & 3.13 & 1.05 & 3.68 & 0.79 & -0.20 & $(-0.44$ & $0.04)$ \\
\hline Average & 3.79 & 0.79 & 3.27 & 0.97 & 3.69 & 0.78 & & & \\
\hline \multicolumn{10}{|l|}{ Hurricane } \\
\hline Qualtrics & 3.54 & 0.95 & 3.48 & 0.81 & 3.52 & 0.95 & -0.01 & $(-0.32$ & $0.29)$ \\
\hline Campus 1 & 3.34 & 0.90 & 3.14 & 1.00 & 3.41 & 0.90 & -0.20 & $(-0.45$ & 0.06) \\
\hline Campus 2 & 3.34 & 0.88 & 2.94 & 1.02 & 3.25 & 0.94 & -0.11 & $(-0.35$ & $0.13)$ \\
\hline Average & 3.39 & 0.91 & 3.15 & 0.96 & 3.37 & 0.93 & & & \\
\hline \multicolumn{10}{|c|}{ Child Sexual Abuse } \\
\hline Qualtrics & 3.66 & 0.95 & 3.82 & 0.71 & 3.50 & 0.99 & 0.27 & $(-0.04$ & $0.57)$ \\
\hline Campus 1 & 3.42 & 0.93 & 3.62 & 0.86 & 3.78 & 0.85 & -0.29 & $(-0.54$ & $-0.03)$ \\
\hline Campus 2 & 3.36 & 0.96 & 3.33 & 1.01 & 3.48 & 0.93 & -0.14 & $(-0.38$ & $0.10)$ \\
\hline Average & 3.46 & 0.95 & 3.56 & 0.88 & 3.59 & 0.92 & & & \\
\hline \multicolumn{10}{|c|}{$\begin{array}{l}\text { Childhood Chronic } \\
\text { Illness }\end{array}$} \\
\hline Qualtrics & 3.43 & 0.91 & 3.44 & 0.79 & 2.93 & 0.98 & 0.57 & $(0.26$ & $0.87)$ \\
\hline
\end{tabular}




\begin{tabular}{llllllllll} 
Campus 1 & 3.41 & 0.67 & 3.32 & 0.92 & 3.28 & 0.85 & 0.11 & $(-0.15$ & $0.36)$ \\
Campus 2 & 3.39 & 0.83 & 3.20 & 0.89 & 3.14 & 0.90 & 0.18 & $(-0.06$ & $0.42)$ \\
Average & 3.41 & 0.79 & 3.30 & 0.88 & 3.14 & 0.90 & & & \\
\hline
\end{tabular}

${ }^{1}$ Cohen's d based on comparison of the combined Redemptive/Survivor endings to the Negative endings.

\section{Hypothesis 4. Narrator Preference: 'Narrators' of redemptive stories will be rated} more positively than the 'narrators' of stories with negative endings.

Study 1. This hypothesis was tested via one-way between-subjects ANOVAs, each examining mean differences in author preference ratings for the six event types. Effect sizes were large and consistent, with the meta-analytic estimate providing strong support for the hypothesis, $d=1.30(1.15,1.46)$ (Table 8 and Figure 4$)$.

Table 8

Descriptive Statistics and Effect Sizes for Study 1 Hypothesis 4: Differences in Narrator Preference

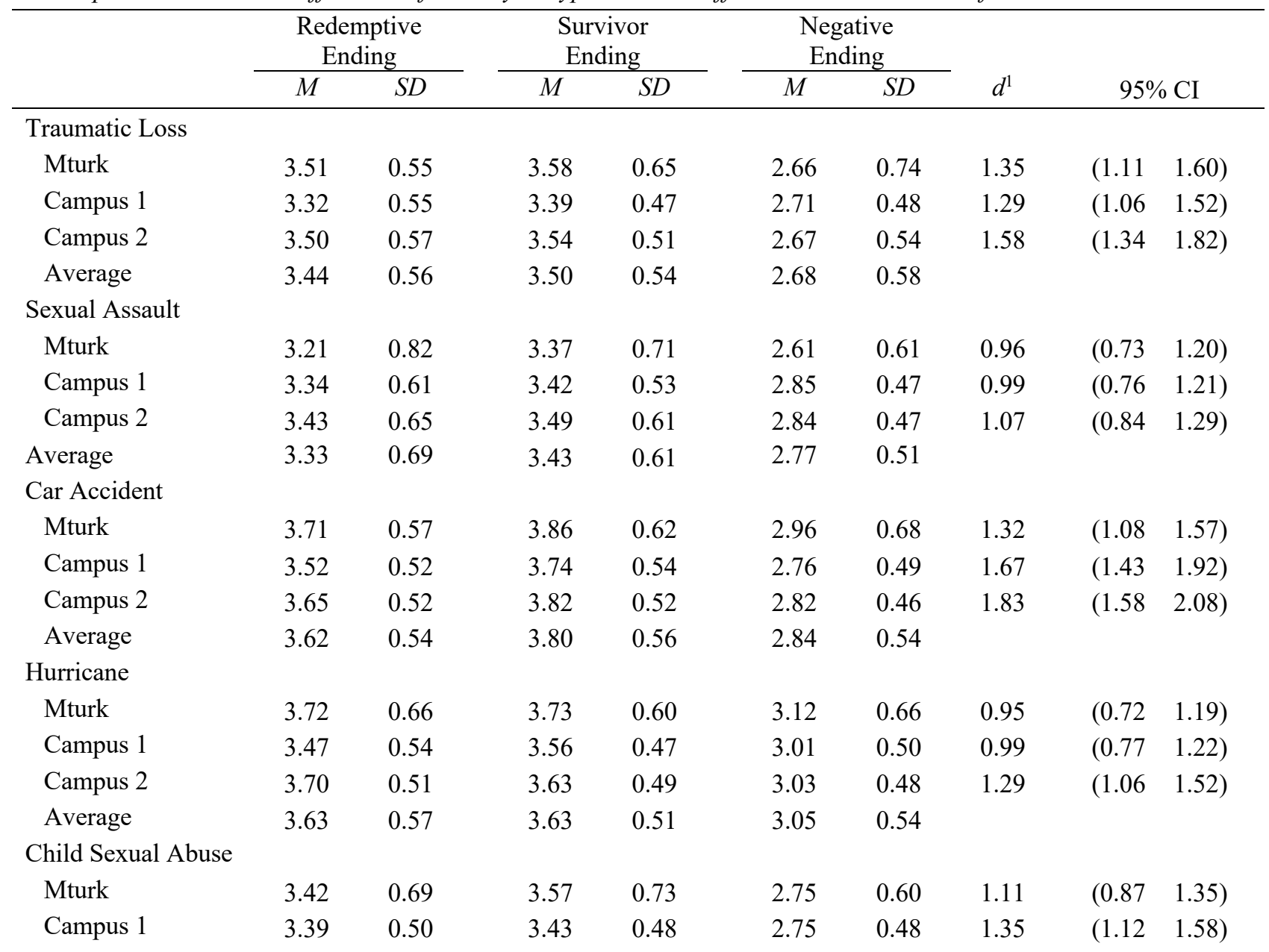


Preferences for Redemption 25

\begin{tabular}{llllllllll} 
Campus 2 & 3.43 & 0.60 & 3.46 & 0.58 & 2.79 & 0.47 & 1.17 & $(0.95$ & $1.39)$ \\
$\quad \begin{array}{l}\text { Average } \\
\text { Childhood }\end{array}$ & 3.41 & 0.59 & 3.48 & 0.59 & 2.76 & 0.51 & & & \\
$\begin{array}{l}\text { Leukemia } \\
\text { Mturk }\end{array}$ & & & & & & & & & \\
Campus 1 & 3.85 & 0.63 & 4.03 & 0.55 & 3.01 & 0.78 & 1.39 & $(1.15$ & $1.64)$ \\
Campus 2 & 3.64 & 0.45 & 3.73 & 0.61 & 2.94 & 0.50 & 1.44 & $(1.21$ & $1.67)$ \\
Average & 3.79 & 0.50 & 3.95 & 0.58 & 2.91 & 0.56 & 1.76 & $(1.51$ & $2.00)$ \\
\hline
\end{tabular}

${ }^{1}$ Cohen's d based on comparison of the combined Redemptive/Survivor endings to the Negative endings.

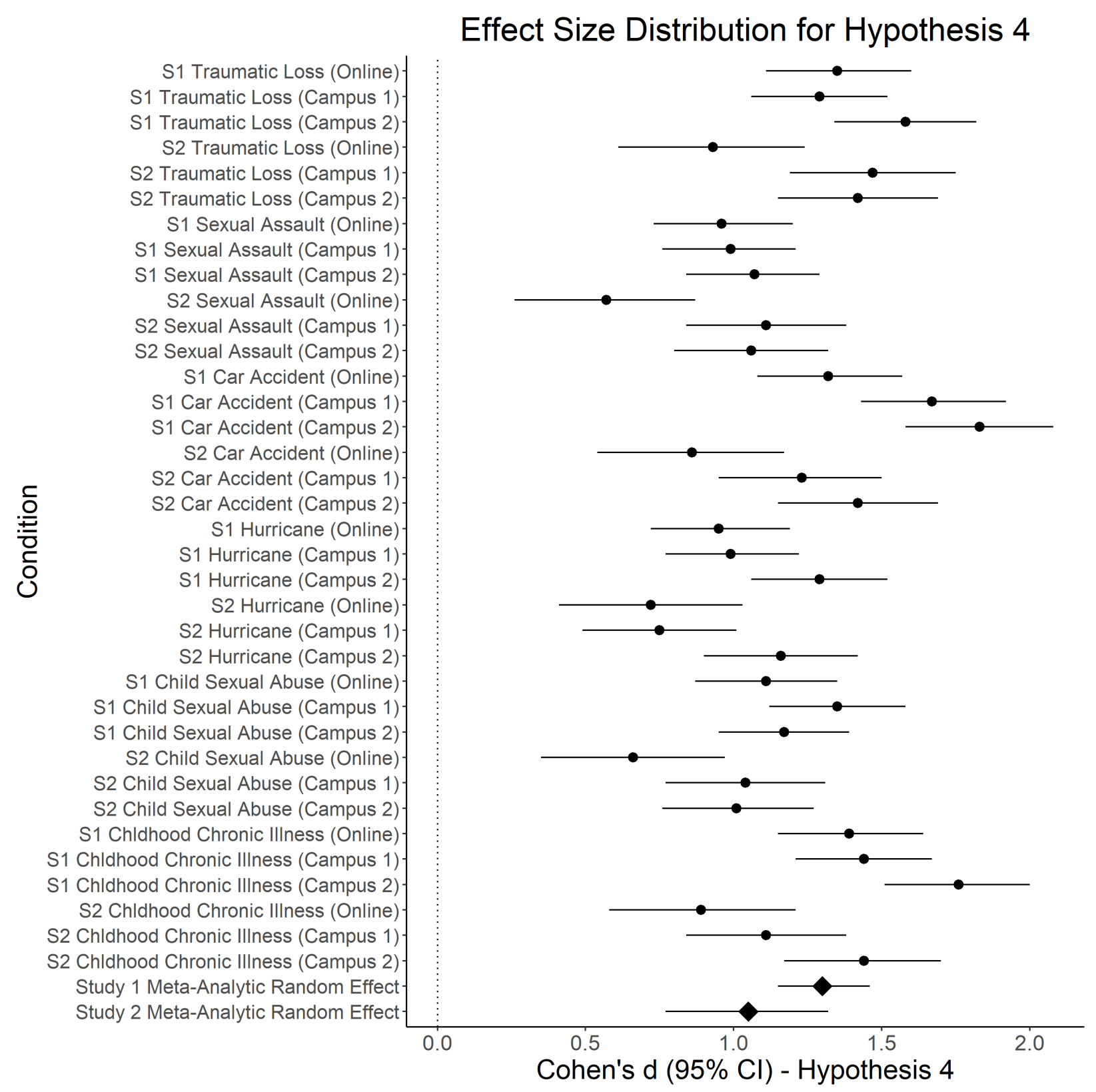

Figure 4. Forest plot for Hypothesis 4 
Study 2. This hypothesis was tested by a 3 (ending) x 6 (event) mixed ANOVA with ending as the between-subjects factor and event as the repeated within-subjects factor. Narrator preference ratings of the stories was the dependent variable, with the between-subjects contrast between redemptive/survivor endings and negative endings as the focal analysis. Results once again provided strong support for the hypothesis, $d=1.05(0.77,1.32)$ (Table 9 and Figure 4).

Table 9

Descriptive Statistics and Effect Sizes for Study 2 Hypothesis 4: Differences in Narrator Preference

\begin{tabular}{|c|c|c|c|c|c|c|c|c|c|}
\hline \multirow{2}{*}{ Traumatic Lo } & \multicolumn{2}{|c|}{$\begin{array}{l}\text { Redemptive } \\
\text { Ending }\end{array}$} & \multicolumn{2}{|c|}{$\begin{array}{l}\text { Survivor } \\
\text { Ending }\end{array}$} & \multicolumn{2}{|c|}{$\begin{array}{c}\text { Negative } \\
\text { Ending }\end{array}$} & \multirow[b]{2}{*}{$d^{1}$} & \multirow{2}{*}{\multicolumn{2}{|c|}{$95 \% \mathrm{CI}$}} \\
\hline & $M$ & $S D$ & $M$ & $S D$ & $M$ & $S D$ & & & \\
\hline Qualtrics & 3.40 & 0.60 & 3.42 & 0.54 & 2.81 & 0.79 & 0.93 & $(0.61$ & $1.24)$ \\
\hline Campus 1 & 3.37 & 0.48 & 3.42 & 0.47 & 2.70 & 0.46 & 1.47 & $(1.19$ & $1.75)$ \\
\hline Campus 2 & 3.35 & 0.51 & 3.43 & 0.56 & 2.64 & 0.51 & 1.42 & $(1.15$ & 1.69) \\
\hline Average & 3.37 & 0.52 & 3.42 & 0.52 & 2.70 & 0.56 & & & \\
\hline \multicolumn{10}{|c|}{ Sexual Assault } \\
\hline Qualtrics & 3.04 & 0.81 & 3.28 & 0.67 & 2.71 & 0.84 & 0.57 & $(0.26$ & $0.87)$ \\
\hline Campus 1 & 3.34 & 0.58 & 3.43 & 0.48 & 2.80 & 0.45 & 1.11 & $(0.84$ & $1.38)$ \\
\hline Campus 2 & 3.43 & 0.57 & 3.38 & 0.58 & 2.81 & 0.51 & 1.06 & $(0.80$ & 1.32) \\
\hline Average & 3.30 & 0.64 & 3.38 & 0.56 & 2.78 & 0.57 & & & \\
\hline \multicolumn{10}{|l|}{ Car Accident } \\
\hline Qualtrics & 3.48 & 0.63 & 3.52 & 0.68 & 2.89 & 0.85 & 0.86 & $(0.54$ & $1.17)$ \\
\hline Campus 1 & 3.49 & 0.47 & 3.53 & 0.57 & 2.90 & 0.45 & 1.23 & $(0.95$ & $1.50)$ \\
\hline Campus 2 & 3.59 & 0.52 & 3.65 & 0.47 & 2.89 & 0.54 & 1.42 & $(1.15$ & 1.69) \\
\hline Average & 3.52 & 0.53 & 3.57 & 0.56 & 2.89 & 0.59 & & & \\
\hline \multicolumn{10}{|l|}{ Hurricane } \\
\hline Qualtrics & 3.56 & 0.61 & 3.38 & 0.66 & 2.95 & 0.82 & 0.72 & $(0.41$ & $1.03)$ \\
\hline Campus 1 & 3.54 & 0.53 & 3.43 & 0.48 & 3.13 & 0.42 & 0.75 & $(0.49$ & $1.01)$ \\
\hline Campus 2 & 3.71 & 0.44 & 3.55 & 0.54 & 3.02 & 0.53 & 1.16 & $(0.90$ & $1.42)$ \\
\hline Average & 3.61 & 0.52 & 3.46 & 0.55 & 3.04 & 0.57 & & & \\
\hline \multicolumn{10}{|c|}{ Child Sexual Abuse } \\
\hline Qualtrics & 3.22 & 0.74 & 3.36 & 0.68 & 2.82 & 0.72 & 0.66 & $(0.35$ & $0.97)$ \\
\hline Campus 1 & 3.34 & 0.54 & 3.37 & 0.50 & 2.84 & 0.43 & 1.04 & $(0.77$ & $1.31)$ \\
\hline Campus 2 & 3.42 & 0.53 & 3.40 & 0.53 & 2.88 & 0.53 & 1.01 & $(0.76$ & $1.27)$ \\
\hline Average & 3.34 & 0.59 & 3.38 & 0.55 & 2.85 & 0.54 & & & \\
\hline \multicolumn{10}{|c|}{$\begin{array}{l}\text { Childhood Chronic } \\
\text { Illness }\end{array}$} \\
\hline Qualtrics & 3.52 & 0.71 & 3.69 & 0.55 & 2.99 & 0.76 & 0.89 & $(0.58$ & $1.21)$ \\
\hline Campus 1 & 3.55 & 0.51 & 3.71 & 0.55 & 3.08 & 0.41 & 1.11 & $(0.84$ & $1.38)$ \\
\hline Campus 2 & 3.73 & 0.49 & 3.90 & 0.48 & 3.06 & 0.59 & 1.44 & (1.17 & $1.70)$ \\
\hline Average & 3.61 & 0.55 & 3.78 & 0.52 & 3.05 & 0.57 & & & \\
\hline
\end{tabular}

${ }^{1}$ Cohen's d based on comparison of the combined Redemptive/Survivor endings to the Negative endings. 
Alternative Test of Hypothesis 4. A preregistered exploratory and alternative test of Hypothesis 4 involved participants' ratings of the authors with respect to the Big Five personality traits. Meta-analyses indicated consistently moderate to large effects wherein authors of redemptive stories were rated more highly in extraversion (Study 1, $d=1.09$ [0.91, 1.27]; Study $2, d=1.81[1.45,2.17]$ ), agreeableness (Study $1, d=0.67[0.55,0.80]$; Study 2, $d=0.61[0.43$, 0.78]), conscientiousness (Study 1, $d=0.65[0.58,0.72]$; Study 2, $d=0.50[0.44,0.57]$ ), emotional stability (Study 1, $d=1.45$ [1.25, 1.66]; Study 2, $d=1.04[0.84,1.24]$ ), and openness (Study $1, d=0.71[0.63,0.80]$; Study $2, d=0.55[0.36,0.74]$ ) in comparison to authors of negative stories (Tables S6 and S7).

\section{Hypothesis 5. Belief in a Just World: Belief in a Just World will Mediate the}

\section{Differences Tested in Hypotheses 1-4.}

Study 1. To test Hypothesis 5 we re-ran the ANOVAs from Hypotheses 1-4 as ANCOVAs controlling for Belief in a Just World. Across five hypothesis, six events, three samples, and two studies - leading to 144 tests overall — the difference in effect size associated with story ending between the original ANOVA and the ANCOVAs was most often zero and never more than negligible (Table 10). Thus, we did not find support for Hypothesis 5. 
Study 2. We followed the same approach as with Study 1 and once again did not find any evidence to support the hypothesis (Table 10).

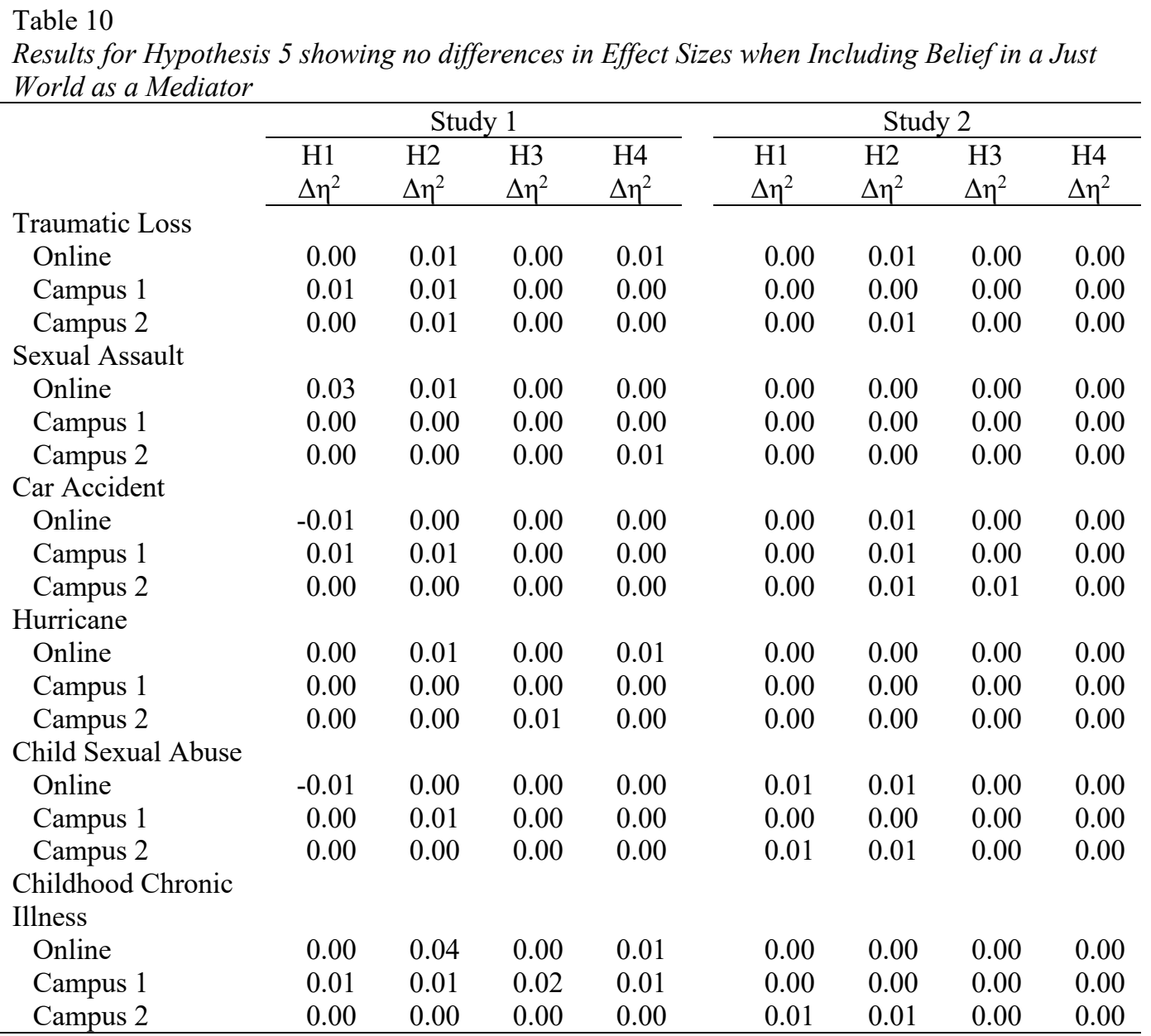

Note. $\Delta \eta^{2}$ is the effect size for the model with Belief in a Just World controlled minus the model without the control. $\mathrm{H}=$ Hypothesis.

\section{Unregistered Exploratory Analysis}

Because of the cultural nature of redemptive storytelling it is possible that individuals not born in the U.S. will have different patterns of responses to the different story endings. The current study was not designed to test this hypothesis, and thus did not intentionally recruit a sufficient number of participants born outside the U.S. Nevertheless, as a sensitivity analysis we re-ran Hypotheses 1-4 after removing the small number of non-U.S. born participants. These models yielded results substantively identical to the original (Table S8). 
An alternative to Hypothesis 5 is that rather than serving as a mediator, Belief in a Just World may be a moderator between ending type and story ratings. As with the test of Hypothesis 5, we re-ran the ANOVAs from Hypotheses 1-4, this time including Belief in a Just World as a moderator of ending type. Across 144 tests only 9 of the tests $(6 \%)$ were statistically significant, and even those were inconsistent across study, hypothesis, and prompt (Table S9). Accordingly, we did not find evidence to support Belief in a Just World as a moderator.

\section{Discussion}

The assumption that those in the U.S. prefer stories of trauma to be redeemed seems obvious and intuitive, but this common assumption has never been empirically tested. Overall, we found strong support for this pervasive, but untested, theoretical claim across multiple types of traumatic events, even after controlling for neuroticism and need for closure, and these findings were robust across two evaluative conditions (between- and within-subjects designs). This trend was seen in the ratings of positivity and the personal preference for these stories, as well as in the positive evaluation of the narrators. Unexpectedly, we did not find that redemption was perceived as more common, or that the relation between story endings and ratings was mediated - or moderated - by Belief in a Just World. We review the results and implications below.

\section{Supported Hypotheses}

Overall, the broad range of participants across these samples reported that traumatic stories that were redeemed were perceived as more positive and preferable than those with negative endings. Participants also perceived the 'narrators' of these studies as healthier and to have more adaptive personality traits. This is consistent with recent work showing that midlife adults who have more redemptive life stories scored higher on more adaptive personality traits 
(higher on agreeableness, conscientiousness, and extraversion, and lower on neuroticism) compared to those with less redemptive life stories (Guo, Klevan, \& McAdams, 2016). The effect sizes observed in all of these analyses were large, much larger than is typically seen in personality research (e.g., Roberts, Kuncel, Shiner, Caspi, \& Goldberg, 2007). These large evaluative effects were obtained by simply changing how the story ended with respect to the narrators' feelings and growth. Results like this raise an interesting question regarding the established finding that those who redeem their negative experiences are also more psychologically healthy (e.g., Adler et al., 2016; McAdams et al., 2001). It has been assumed that the primary explanation for this association is that there is something inherently beneficial about redemption as a way to make meaning of challenging experiences (e.g., McAdams et al., 2001). However, it might also be the case that telling such stories allows for a feeling of interpersonal validation and connection, which explains positive psychological functioning.

Beyond confirming theoretical propositions, these results illuminate the potential for real challenge during the process of sharing stories that do not align with expectations. First, in contexts of interpersonal storytelling, as well as therapeutic contexts, someone who does not redeem trauma may be unheard, devalued, or isolated. These individuals may also be the most in need of support to promote recovery, but if both their stories and their selves are viewed less positively, they may the least likely to receive that needed support. Second, the pressure to conform to cultural master narratives may result in some people not telling fully authentic stories, limiting our ability to truly know each other, one of the hallmark functions of personal storytelling (McAdams, 1995). Finally, at the most global level, the preference for the redemption of trauma may create expectations that trauma is always redeemable by the 
individual, leaving the larger collective social and political responsibility to address and prevent trauma unaddressed.

Indeed, although not the focus here (see Delker et al., 2020), there are some hints that some stories may be especially hard to tell, even when they are redeemed. The stories of childhood sexual abuse and adult sexual assault were rated less positively than other stories even when they were redeemed. Given the prevalence of such experiences (Centers for Disease Control and Prevention, 2019), it is important to consider the cultural and interpersonal messages that might impact the ability to share one's story, as well as the larger responsibility for managing (and preventing) such traumas (Delker, Salton, \& McLean, 2019; Delker et al., 2020).

\section{Unsupported Hypotheses}

We did not find that redemptive stories were viewed as particularly common. This was unexpected, and there are several possibilities in interpreting this hypothesis. The first is that redemption is not a master narrative. McLean and Syed (2015) pointed to the importance of 'air time' in determining master narratives - that is, those stories that are heard and told frequently are more likely to serve as master narratives (see also McLean, Fordham, Boggs, Byers, Haraldsson, Lowe, \& Syed, 2019; McLean, Shucard, \& Syed, 2017). If this proposition is true, then these results suggest that redemption is not a master narrative. However, our other results concerning the preference for different types of stories provide support for the notion that redemption is a master narrative. Thus, one possibility is that there may be a range to how much a particular narrative serves as a master narrative, and redemption may only hit some of the key principles identified by McLean and Syed (2015).

An alternative interpretation is that frequency may not be key in determining a master narrative. Given the findings that narrators of redemptive stories are perceived more positively, 
perhaps a more central ingredient to determining master narratives is not how often they are told, but who is telling the stories and how they, in turn, are perceived. This interpretation is consistent with the idea that those in certain positions of power (in this case those who are liked, viewed as healthy) have greater influence on determining or communicating what the 'right' or 'good' story is (McLean \& Syed, 2015). Indeed, there exists a 'prestige bias' such that norms are not defined by their commonality, but by what is transmitted by those with greater prestige (Henrich, Boyd, \& Richerson, 2008).

It is also possible that not all of our hypotheses were supported because we are examining something live and dynamic - culture. Indeed, cultural norms and expectations about how to tell stories of trauma could be shifting. For example, those in positions of power may still be emphasizing the status quo, and those in marginalized and/or minority groups may see a different story to tell, perhaps one that emphasizes struggle and work to be done, rather than neat resolutions that negate the need for change (e.g., Eibach \& Ehrlinger, 2006). Examining how these stories are perceived by people in different positions of power is an important next step. Finally, although McLean and Syed (2015) proposed the principles for defining master narratives, there is not an agreed upon method of determining if a story is a master narrative. We examined prevalence of stories, but others have examined associations between story types and well-being, with the assumption that story types associated with higher well-being are more likely to be master narratives (e.g., Eriksson et al., 2019). Finally, our measure of narrative ubiquity may not have been optimal. The measure only consisted of two items asking whether the story was common, not whether the ending was common. Either way, such questions may be difficult to answer, and we encourage researchers to consider more novel ways of testing this hypothesis. In short, master narratives are a complex phenomenon and data like those presented 
here add to the methodological toolbox and discussion of how best to examine these dynamic cultural stories.

We also did not find support for Belief in a Just World as a mediator of relations between story ending and preferences for stories and 'narrators,' nor did we find support for it as a moderator in the exploratory analyses. Given the consistent replication of these null finding, we think it is safe to say that Belief in a Just World does not serve as a mediator or moderator, at least as measured with this scale. Perhaps the preference findings indicate that the response to redemption is about managing listeners' own emotional reaction to the stories, making them feel better about themselves or feel better for the teller, rather than restoring a more abstract schema about the way the world operates. In hindsight, this hypothesis may not have been well thoughtout. Although individual differences can be mediators of experimental manipulations (Pirlott \& MacKinnon, 2016), this situation is difficult to justify, and even so, we should have used a state rather than trait measure of Belief in a Just World.

\section{Limitations and Conclusions}

Despite the strengths of our large and varied samples and robust replication, we do raise some limitations. First, we have some concepts measured with a single-item or two-item assessment. Although this is common in large-scale self-report studies for relatively face valid constructs (e.g., Cheung \& Lucas, 2014), there can be drawback to the reliability and validity of the assessments (though the consistency of our findings across ratings alleviates some of these concerns). Second, we did not examine whether this is solely a phenomenon in the U.S., as is claimed (McAdams, 2006; see also Eriksson, McLean, \& Frisén, 2019; Blackie, Colgan, McDonald, \& McLean, 2019), though documenting the effect before engaging in cross-cultural work is logical, and provides a strong starting point from cross-cultural examinations. 
Constraints on Generality. Following Simons, Shoda, and Lindsay (2017), we note that our target population was US adults, and we sampled emerging adult college students at two geographically distinct public universities, and adults willing and able to complete research studies in on on-line platform. Although this is a relatively broad range of participants, we do not have the power, nor did we sample with the intention, to examine various demographic characteristics (e.g., broad age range, immigration status, racial/ethnic background, sexuality, etc.) to determine the extent of the generalizability of our samples.

In conclusion, these findings support the previously untested claim that there is a preference for redemptive stories, and the 'redemptive self' (McAdams, 2006). As such, they hold implications for the way we think about the role of cultural scaffolds and expectations for narrative identity. They also underscore the weight of these expectations for the individual, and the risk of leaving the cultural and social responsibility for preventing and managing trauma untouched. Creating awareness of this cultural and personal preference, which may be somewhat unconscious (McLean \& Syed, 2015), may alleviate some of the unintended pressure placed on those who have experienced trauma that is unredeemed. 


\section{References}

Adler, J.M., Lodi-Smith, J., Philippe, F.L., Houle, I. (2016). The incremental validity of narrative identity in predicting well-being: A review of the field and recommendations for the future. Personality and Social Psychology Review, 20(2), 142-175. doi:

\section{$10.1177 / 1088868315585068$}

Blackie, E. R., Colgan, J., McDonald, S., McLean, K. C. (2019). A Qualitative Investigation into the Cultural Master Narrative for Overcoming Trauma and Adversity in the United Kingdom. Qualitative Psychology.

Bullock, J. G., Green, D. P., \& Ha, S. E. (2010). Yes, But What's the Mechanism?(Don't Expect an Easy Answer). Journal of Personality and Social Psychology, 98(4), 550-558.

Cheung F. \& Lucas, R. E. (2014). Assessing the validity of single-item life satisfaction measures: Results from three large samples. Quality of Life Research, 23, 2809-2818. doi: 10.1007/s11136-014-0726-4

Cox, K. \& McAdams, D. (2014). Meaning Making during High and Low Point Life Story Episodes Predicts Emotion Regulation Two Years Later: How the Past Informs the Future. Journal of Research in Personality. 50. 10.1016/j.jrp.2014.03.004.

Delker, B., Salton, R., \& McLean, K. C. (2019). Giving voice to silence: Empowerment and disempowerment in the developmental shift from trauma 'victim' to 'advocate.' Journal of Trauma and Dissociation, 21:2, 242-263.

Delker, B. C., Salton, R., McLean, K. C., \& Syed, M. (2020). Who has to tell their trauma story and how hard will it be? Influence of cultural stigma and narrative redemption on the storying of sexual violence. PLOS One. https://doi.org/10.1371/journal.pone.0234201

Dunlop, W. L., \& Tracy, J. L. (2013). Sobering stories: Narratives of self-redemption predict 
behavioral change and improved health among recovering alcoholics. Journal of Personality and Social Psychology, 104, 576-590. doi: 10.1037/a0031185

Eriksson, P. L., McLean, K. C., \& Frisén, A. (2018). Taking the Bad With the Good - A Cultural Framework for Identity Narratives of Difficult Experiences in Sweden. Manuscript Under Review.

Fivush, R. (2010). Speaking silence: The social construction of silence in autobiographical and cultural narratives. Memory, 18, 88-98. doi: 10.1080/09658210903029404

Furnham, A. (2003). Belief in a just world: Research progress over the past decade. Personality and Individual Differences, 34(5), 795-817. http://dx.doi.org/10.1016/S0191$\underline{8869(02) 00072-7}$

Goh, J. X., Hall, J. A., \& Rosenthal, R. (2016). Mini meta-analysis of your own studies: Some arguments on why and a primer on how. Social and Personality Psychology Compass, 10(10), 535-549. http://dx.doi.org/10.1111/spc3.12267

Gosling, S. D., Rentfrow, P. J., \& Swann, W. B., Jr. (2003). A very brief measure of the Big-Five personality domains. Journal of Research in Personality, 37(6), 504-528. http://dx.doi.org/10.1016/S0092-6566(03)00046-1

Guo, J., Klevan, M., \& McAdams, D. P. (2016). Personality traits, ego development, and the redemptive self. Personality and Social Psychology Bulletin, 42(11), 1551-1563. https://doi.org/10.1177/0146167216665093

Hammack, P. L. (2008). Narrative and the cultural psychology of identity. Personality and Social Psychology Review, 12(3), 222-247. doi/10.1177/1088868308316892

Henrich, J., Boyd, R., \& Richerson, P. J. (2008). Five misunderstandings about cultural evolution. Human Nature, 19(2), 119-137. https://doi.org/10.1007/s12110-008-9037-1 
IBM Corp. (2016). IBM SPSS Statistics for Windows, Version 24.0. Armonk, NY: IBM Corp.

Kelley, K. (2019). MBESS: The MBESS R Package. R package version 4.6.0. https://CRAN.Rproject.org/package $=$ MBESS

Lilgendahl, J. P., \& McAdams, D. P. (2011). Constructing stories of self-growth: How individual differences in patterns of autobiographical reasoning relate to well-being in midlife. Journal of Personality, 79, 391-428. http://dx.doi.org/10.1111/j.1467-6494.2010.00688.x

Lilgendahl, J. P., \& McLean, K. C. (2019). Narrative Identity Processes and Changes in Wellbeing Across the Transition to College: A Contextualized Approach. Journal of Personality and Social Psychology: PPID.

Lucas, T., Zhdanova, L., \& Alexander, S. (2011). Procedural and distributive justice beliefs for self and others: Assessment of a four-factor individual differences model. Journal of Individual Differences, 32(1), 14-25. http://dx.doi.org/10.1027/1614-0001/a000032

McAdams, D. P. (1995). What do we know when we know a person? Journal of Personality, 63, 365-396. https://doi.org/10.1111/j.1467-6494.1995.tb00500.x

McAdams, D. P. (2006). The redemptive self: Stories Americans live by. New York: Oxford University Press.

McAdams, D. P. (2008). American identity: The redemptive self. The General Psychologist: 43, $20-27$.

McAdams, D. P., \& Guo, J. (2015). Narrating a generative life. Psychological Science, 26, 475483. doi/10.1177/0956797614568318

McAdams, D. P., \& McLean, K. C. (2013). Narrative Identity. Current Directions in Psychological Science, 22, 233-238. doi/abs/10.1177/0963721413475622 
McAdams, D. P., \& Pals, J. L. (2006). A new Big Five: Fundamental principles for an integrative science of personality. American Psychologist, 61, 204-217. DOI: 10.1037/0003066X.61.3.204

McLean, K. C., Fordham, C., Boggs, S., Byers, S., Haraldsson, K., Lowe, L., Syed, M. (2019). Personal Identity Development in Cultural Context: The Socialization of Master Narratives about the Gendered Life Course. International Journal of Behavioral Development. doi.org/10.1177/0165025419854150

McLean, K. C., Lilgendahl, J. P., Fordham, C., Alpert, L., Marsden, E., \& Szymanowski, K., \& McAdams, D. P. (2017). Master Identity Development in Cultural Context: The Role of Deviating from Master Narratives. Journal of Personality, 65, 1 - 21. doi: 10.1111/jopy. 12341

McLean, K. C., \& Pratt, M. W. (2006). Life's little (and big) lessons: Identity statuses and meaning-making in the turning point narratives of emerging adults, Developmental Psychology, 42, 714-722. DOI:10.1037/0012-1649.42.4.714

McLean, K. C., Shucard, H., \& Syed, M. (2017). Applying the Master Narrative Framework to Gender Identity in Emerging Adulthood: Emerging Adulthood, 5, 93-105. http://dx.doi.org/10.1177/2167696816656254

McLean, K. C. \& Syed, M. (2015). Personal, Master, and Alternative Narratives: An Integrative Framework for Understanding Identity Development in Context. Human Development, 58, 318 - 349. https://doi.org/10.1159/000445817

Pirlott, A. G., \& MacKinnon, D. P. (2016). Design approaches to experimental mediation. Journal of Experimental Social Psychology, 66, 29-38.

R Core Team (2019). R: A language and environment for statistical computing. R Foundation for 
Statistical Computing, Vienna, Austria. URL https://www.R-project.org/.

Roberts, B. W., Kuncel, N. R., Shiner, R., Caspi, A., \& Goldberg, L. R. (2007). The power of personality: The comparative validity of personality traits, socioeconomic status, and cognitive ability for predicting important life outcomes. Perspectives on Psychological science, 2(4), 313-345.

Roets, A. \& Van Hiel, A. (2011). Item selection and validation of a brief, 15-item version of the Need for Closure Scale. Personality and Individual Differences, 50, 90-94.

Simons, D. J., Shoda, Y., \& Lindsay, D. S. (2017). Constraints on generality (COG): A proposed addition to all empirical papers. Perspectives on Psychological Science, 12(6), 11231128.

Soto, C., \& John, O. (2017). The Next Big Five Inventory (BFI-2): Developing and Assessing a Hierarchical Model With 15 Facets to Enhance Bandwidth, Fidelity, and Predictive Power. Journal of Personality and Social Psychology, 113(1), 117-143.

Viechtbauer, W. (2010). Conducting meta-analyses in R with the metafor package. Journal of Statistical Software, 36(3), 1-48. URL: http://www.jstatsoft.org/v36/i03/

Wickham, H. (2016). ggplot2: Elegant Graphics for Data Analysis. Springer-Verlag: New York, Centers for Disease Control and Prevention (2019). Preventing sexual violence. Retrieved from https://www.cdc.gov/violenceprevention/sexualviolence/fastfact.html 